University of Wollongong

Research Online

Faculty of Engineering and Information

Faculty of Engineering and Information

Sciences - Papers: Part B

Sciences

2018

Experimental investigation of CFRP confined hollow core Reactive Powder Concrete columns

Muhammad N. S Hadi

University of Wollongong, mhadi@uow.edu.au

Hussamaldeen GOAIZ

University of Wollongong, hagao106@uowmail.edu.au

Tao Yu

University of Wollongong, taoy@uow.edu.au

Follow this and additional works at: https://ro.uow.edu.au/eispapers1

Part of the Engineering Commons, and the Science and Technology Studies Commons

Research Online is the open access institutional repository for the University of Wollongong. For further information contact the UOW Library: research-pubs@uow.edu.au 


\title{
Experimental investigation of CFRP confined hollow core Reactive Powder Concrete columns
}

\author{
Abstract \\ This paper presents an experimental investigation on the behaviour of hollow core Reactive Powder \\ Concrete (HCRPC) columns confined with a circular Carbon-Fibre-Reinforced polymer (CFRP) tube. \\ Sixteen circular hollow core specimens $(206 \mathrm{~mm}$ in diameter, $800 \mathrm{~mm}$ in height and a $90 \mathrm{~mm}$ circular \\ hole) were made with Reactive Powder Concrete (RPC) of $105 \mathrm{MPa}$ compressive strength. These \\ specimens were divided into four groups. The first group was the control group that consisted of four \\ unconfined HCRPC specimens reinforced with conventional longitudinal steel bars and steel helices. The \\ specimens of the second group had the same configuration as the first group except that these \\ specimens were externally confined with CFRP tube. The specimens of the third group were externally \\ confined with a CFRP tube and internally confined with a Polyvinyl chloride (PVC) tube. Finally, the \\ specimens of the fourth group had no steel reinforcement and were only made with an external CFRP \\ tube and an internal steel tube. These specimens were subjected to different loading conditions: \\ concentric, eccentric $(25 \mathrm{~mm}$ and $50 \mathrm{~mm}$ ) and four-point bending. It was found that the CFRP tube \\ confinement slightly increased the strength of the HCRPC columns, whereas the ductility was significantly \\ enhanced. In addition, by introducing the PVC tube as internal confinement to the hollow columns the \\ ductility was also improved.

\section{Disciplines} \\ Engineering | Science and Technology Studies

\section{Publication Details} \\ Hadi, M. N. S., Goaiz, H. A. \& Yu, T. (2018). Experimental investigation of CFRP confined hollow core \\ Reactive Powder Concrete columns. Construction and Building Materials, 174 343-355.
}




\title{
Experimental Investigation of CFRP Confined Hollow Core Reactive Powder Concrete Columns
}

\author{
Muhammad N.S. Hadi ${ }^{1, *}$ \\ ${ }^{1}$ Associate Professor, School of CME Engineering, University of Wollongong, Australia. \\ Email: mhadi@uow.edu.au, ${ }^{*}$ Corresponding author \\ Hussam A. Goaiz ${ }^{2}$ \\ ${ }^{2} \mathrm{PhD}$ Candidate, School of CME Engineering, University of Wollongong, Australia. \\ Email: hagao106@uowmail.edu.au
Tao $\mathrm{Yu}^{3}$
${ }^{3}$ Associate Professor, School of CME Engineering, University of Wollongong, Australia. Email: taoy@uow.edu.au

\section{Abstract}

This paper presents an experimental investigation on the behaviour of hollow core Reactive Powder Concrete (HCRPC) columns confined with a circular Carbon-Fibre-Reinforced polymer (CFRP) tube. Sixteen circular hollow core specimens (206 $\mathrm{mm}$ in diameter, $800 \mathrm{~mm}$ in height and a $90 \mathrm{~mm}$ circular hole) were made with Reactive Powder Concrete (RPC) of 105 $\mathrm{MPa}$ compressive strength. These specimens were divided into four groups. The first group was the control group that consisted of four unconfined HCRPC specimens reinforced with conventional longitudinal steel bars and steel helices. The specimens of the second group had the same configuration as the first group except that these specimens were externally confined with CFRP tube. The specimens of the third group were externally confined with a CFRP tube and internally confined with a Polyvinyl chloride (PVC) tube. Finally, the specimens of the fourth group had no steel reinforcement and were only made with an external CFRP tube and an internal steel tube. These specimens were subjected to different loading conditions: concentric, eccentric $(25 \mathrm{~mm}$ and $50 \mathrm{~mm})$ and four-point bending. It was found that the CFRP 
tube confinement slightly increased the strength of the HCRPC columns, whereas the ductility was significantly enhanced. In addition, by introducing the PVC tube as internal confinement to the hollow columns the ductility was also improved.

Keywords: Reactive Powder Concrete, CFRP tube, hollow columns, PVC tube

\section{Introduction}

In a structural design where reducing concrete weight and cost is preferred, a desirable option is to use hollow reinforced concrete members. The advantage of using hollow reinforced vertical members is to enhance the structural performance of the strength/mass and stiffness/mass ratios. The behaviour of hollow concrete columns can be significantly improved by using a high-strength concrete with high ductility such as Reactive Powder Concrete (RPC). Because this type of concrete can be a preferable option for structural designers to compensate the reduction of the axial load capacity in hollow core concrete columns due to the effect of the hollow core.

The RPC is a relatively new type of ultra-high performance concrete characterized by its ultrahigh strength, low permeability and high ductility. This high ductility and energy absorption are due to the presence of a significant amount of steel fibre within the composition of the RPC. Compared to normal concrete, RPC presents more homogeneity between the components and this minimizes the differential tensile strain and maximizes the load carrying capacity of this type of concrete [1].

Over the last few decades, Fibre-Reinforced Polymer (FRP) has become a widespread technique in concrete retrofitting. In addition, new concrete members can be confined with FRP tubes where the FRP tube is also used as a stay-in-place form. This type of FRP 
confinement was investigated not only with conventional concrete but with different types of concrete in several studies [2-11].

For hollow core concrete columns, a Carbon-Fibre-Reinforced polymer (CFRP) tube can be used to compensate the reduction in the ultimate axial load, which is caused by the existence of an inner hole within the columns' cross section. In order to obtain further understanding of the behaviour of FRP confined hollow core concrete columns, a number of studies have been performed [12-17].

Lingola et al. [13] conducted an experimental and analytical study on CFRP confined hollow square cross section concrete columns. The strength and ductility behaviour of these columns were investigated under concentric and eccentric loading conditions. It was shown that the strength of hollow columns is increased and the ductility is significantly enhanced.

There are a number of different factors, which can affect the behaviour of FRP confined hollow reinforced concrete columns, such as hollow core size and shape; FRP type and thickness; and concrete type and strength. Kusumawardaningsih and Hadi [15] studied the shape influence of inner hole on the effectiveness of FRP confinement. It was found that using a circular hollow core had better performance than using a square hollow core in terms of improving the strength and ductility of FRP confined hollow columns.

Hadi and Le [17] conducted an experimental study to investigate the behaviour of hollow core concrete columns wrapped with CFRP sheets. These columns were wrapped with CFRP sheets in three different combinations of wrapping orientations $\left(0^{\circ}, 45^{\circ}\right.$ and $90^{\circ}$ with respect to the circumferential direction). It was found that the strength and ductility of hollow core concrete columns were increased for all wrapping configurations but the increase in the strength was minor. The highest results of strength and ductility were obtained with columns that were exclusively wrapped with CFRP sheets in the hoop direction. 
Hollow concrete columns that are externally confined with FRP can also be internally confined with a steel tube to form a hybrid FRP-concrete-steel member, according to Teng et al. [18]. By using an inner steel tube, both the strength and ductility of FRP confined hollow concrete columns are improved. Several studies have been conducted to investigate the behaviour of such columns under axial compression and flexural loading conditions [19-23].

The internal tube used in the existing studies, however, generally had a large stiffness and served as longitudinal reinforcement. The use of a stiff internal tube is inefficient in resisting bending for hollow columns with a relatively small void and may be unnecessary for constraining the inner surface of concrete. Thus, a less stiff internal tube such as PVC tube is more suitable than the steel tube to restrain the inner surface of concrete for effective confinement. The use of the PVC tube in the construction has the advantages of the low cost, outstanding durability, lightweight material and ease of installation. Against this background, this study presents a new type of FRP-confined hollow columns with an internal PVC tube.

The aim of this study is to investigate the behaviour of steel reinforced hollow core RPC (HCRPC) circular columns confined with external CFRP tubes and to examine the efficiency of the internal PVC tube in enhancing both the strength and ductility of this type of column.

\section{Experimental Program}

In this study, the experimental program was conducted in the Highbay Laboratory of the School of Civil, Mining and Environmental Engineering at the University of Wollongong, Australia. The details of the experimental program are explained below.

\subsection{Design of Specimens}

Sixteen circular HCRPC short concrete specimens having the dimensions of $206 \mathrm{~mm}$ in diameter, $800 \mathrm{~mm}$ in height and a $90 \mathrm{~mm}$ in diameter hole were made with RPC of 
compressive strength of $105 \mathrm{MPa}$ at 28 days. These specimens were divided into four groups.

The first group (Group R) was the control group consisting of four unconfined HCRPC specimens reinforced with six deformed steel bars N12 (12 mm diameter deformed bars with a nominal tensile strength of $500 \mathrm{MPa}$ ) as longitudinal reinforcement. Plain steel bars R10 (10 mm diameter plain bars with a nominal tensile strength of $250 \mathrm{MPa}$ ) were used as helices with a pitch of $50 \mathrm{~mm}$. The design of the steel reinforcement in this study meets the requirements of the Australian Standard (AS) 3600 [24] for concrete structures. The specimens of the second group (Group CR) had the same configuration as the first group except they were externally confined with a $1.5 \mathrm{~mm}$ thick CFRP tube. The specimens of the third group (Group CRP) were externally confined with a $1.5 \mathrm{~mm}$ thick CFRP tube and internally confined with a $3.5 \mathrm{~mm}$ thick Polyvinyl chloride (PVC) tube. Finally, the specimens of the fourth group (Group CS) had no conventional steel reinforcement and they were made with a $1.5 \mathrm{~mm}$ thick external CFRP tube, a $3.5 \mathrm{~mm}$ thick internal steel tube and RPC in between. In the column design of the fourth group, a steel tube was selected in order to obtain an equivalent axial load capacity to the steel bars that are used in the column design of the other groups. The geometry of the specimens is presented in Figure 1 and Table 1.

\subsection{Specimens Labelling System}

For the purposes of this study, each specimen is identified with an acronym. The symbol $\mathrm{R}$ refers to the use of steel bar reinforcement. The symbol C stands for confinement with a CFRP tube. The symbols $\mathrm{P}$ and $\mathrm{S}$ refer to the presence of an inner PVC tube and steel tube within the specimen, respectively. Finally, the numbers $0,25,50$ and the letter $B$ indicate that the specimen is tested under concentric load, $25 \mathrm{~mm}$ eccentric load, $50 \mathrm{~mm}$ eccentric load and four-point bending, respectively. For example, Specimen CR50 is steel reinforced specimen confined with an external CFRP tube and subjected to $50 \mathrm{~mm}$ eccentric load and Specimen 
CSB is confined with an external CFRP tube, internal steel tube and subjected to four-point bending.

\subsection{Material Properties}

\subsubsection{Reactive Powder Concrete}

In this study, due to the load capacity limitation of the testing machine, the HCRPC specimens were designed to obtain a compressive strength of $100 \mathrm{MPa}$ at 28 days. To achieve the targeted compressive strength of the RPC in this study, several trial mixes were conducted in order to determine the mix proportion of each material. The RPC was made with commercially available materials: General Purpose cement $800 \mathrm{~kg} / \mathrm{m}^{3}$, fine sand $1050 \mathrm{~kg} / \mathrm{m}^{3}$, densified silica fume $250 \mathrm{~kg} / \mathrm{m}^{3}$, water $180 \mathrm{~kg} / \mathrm{m}^{3}$, superplasticizer $60 \mathrm{~kg} / \mathrm{m}^{3}$ and steel fibre $160 \mathrm{~kg} / \mathrm{m}^{3}(2 \%$ by volume of concrete). A straight shape steel fibre with an ultimate tensile strength of $2500 \mathrm{MPa}$ was provided by Ganzhou Daye Metallic Fibres [26]. The length and the diameter of the steel fibre were $13 \mathrm{~mm}$ and $0.2 \mathrm{~mm}$, respectively. The effect of steel fibre content on the mechanical properties of the RPC has been investigated by Goaiz et al. [27] and it was found that the highest strength and ductility of the RPC were achieved using 3\% steel fibre volume content. Although $3 \%$ of steel fibre showed the highest strength results but $2 \%$ of steel fibre was used in this study to reinforce the RPC. Because when $3 \%$ of steel fibre is used, the flowability of the RPC mix dramatically decreased which created some issues associated with mixing and pouring this type of concrete, especially in steel reinforced thin sections (hollow core sections). By using $2 \%$ of steel fibre content, the uniaxial tensile strength was nearly $7 \%$ of the compressive strength at the age of 28 days. In addition, no strain hardening in the tensile stressstrain behaviour was achieved with $2 \%$ steel fibre content. Accordingly, the contribution of the steel fibre to the HCRPC circular columns under bending loading can be ignored. 
152 An electronic balance was used to batch all the dry materials that were mixed in a laboratory mixer of $0.1 \mathrm{~m}^{3}$ capacity. Then, the water and the polycarboxylate superplasticizer admixture, which complied with the specifications ASTM C494 [28], were added to the dry mixture. After a period of 10 minutes of mixing, the full amount of steel fibre was added and the desired flowability (Flow table test $>120 \mathrm{~mm}$ ) was obtained in accordance with ASTM C230 [29]. The fresh RPC was then placed into the formwork that consisted of four PVC pipes and twelve CFRP tubes vertically fixed on a wooden base. During the process of concrete placing, an electric vibrator was used to compact and eliminate air voids. Wet hessian and plastic sheets were used for curing and covering the specimens for a period of 28 days. Three concrete cylinders with the dimensions of $100 \mathrm{~mm}$ in diameter and $200 \mathrm{~mm}$ in height were tested at the age of 7, 28 days and the day of the test according to AS 1012.9 [25] to determine the compressive strength. The average values of the compressive strength at the age of 7 days, 28 days and the day of the test were $78 \mathrm{MPa}, 105 \mathrm{MPa}$ and $116 \mathrm{MPa}$, respectively.

\subsubsection{CFRP tube}

The filament-wound CFRP tubes of $1.5 \mathrm{~mm}$ thickness were manufactured by Composite Spars and Tubes Company based in Caringbah, NSW, Australia [30]. These tubes consisted of two layers. The inner layer $(0.5 \mathrm{~mm}$ thickness $)$ was orientated in the longitudinal direction with a $0^{\circ}$ winding angle, while the outer layer (1.0 mm thickness) was orientated in the hoop direction with an $89^{\circ}$ winding angle. Three CFRP coupons with a $250 \mathrm{~mm}$ total length, a $138 \mathrm{~mm}$ test length and a $25 \mathrm{~mm}$ width, were cut out of the longitudinal direction of the tube to determine the CFRP tensile properties. The CFRP coupon test was conducted according to the standard ASTM D3039 [31]. Based on the test results of the three samples, the average values of ultimate tensile strength, modulus of elasticity and ultimate tensile strain were $604 \mathrm{MPa}, 46$ 
the hoop direction, tensile split-disk tests were conducted on three CFRP rings. The rings with dimensions of $35 \mathrm{~mm}$ in width and $1.5 \mathrm{~mm}$ in thickness were cut from the same CFRP tube. The split-disk test was conducted in accordance with the ASTM D2290 [32] standard. The average values of ultimate tensile strength, modulus of elasticity and ultimate tensile strain were $1160 \mathrm{MPa}, 86 \mathrm{GPa}$, and $1.31 \%$, respectively.

\subsubsection{PVC tube}

The PVC tube with an inner diameter of $90 \mathrm{~mm}$ and a thickness of $3.5 \mathrm{~mm}$ was used in this study. Three coupons having the dimensions of $165 \mathrm{~mm}$ in total length, $57 \mathrm{~mm}$ in test length and $13 \mathrm{~mm}$ in test width were taken from the longitudinal direction of the PVC tube to obtain the tensile stress-strain relationship of this material according to ASTM D638 [33]. Figure 2 shows the dimensions of the PVC coupon and the typical tensile stress-strain behaviour of PVC material, the average values of the ultimate tensile strength, strain and the modulus of elasticity were $63.4 \mathrm{MPa}, 43.7 \%$ and $4.1 \mathrm{GPa}$, respectively. Three samples of the PVC tube with a length of $800 \mathrm{~mm}$ were tested in axial compression to determine the maximum axial load capacity of the tube. The average maximum axial load of the PVC tubes under compression was $54 \mathrm{kN}$.

\subsubsection{Steel tube}

In this study, steel tubes with an inner diameter of $90 \mathrm{~mm}$ and a thickness of $3.5 \mathrm{~mm}$ were used. Tensile tests on three steel coupons were extracted from one batch of steel tube. The coupons having the dimensions of $300 \mathrm{~mm}$ in total length, $120 \mathrm{~mm}$ in test length and $20 \mathrm{~mm}$ in test width were cut from the steel tube along the longitudinal direction and were tested according to the AS 1391.07 [34]. The average values of the modulus of elasticity, yield strength, and 
ultimate tensile strength of the steel tubes were $200 \mathrm{GPa}, 430 \mathrm{MPa}$ and $500 \mathrm{MPa}$, respectively.

202

203

204

205

206

207

208

209

210

211

212

213

214

215

216

217

218

219

220

221

222

The peak axial load of the steel tube was determined by testing three samples $(800 \mathrm{~mm}$ in length) of the tube under axial compression. The average peak axial load of the steel tubes was $320 \mathrm{kN}$.

\subsection{Instrumentation}

In order to obtain the load-deformation test results of the HCRPC specimens, a Denison testing machine with a loading capacity of $5000 \mathrm{kN}$ was used. To prevent premature failure of the column ends during the test, a single layer of CFRP sheet with a width of $100 \mathrm{~mm}$ was used to wrap the top and the bottom of the column specimens. In all loading cases of the specimens, the results of axial deformation were recorded with two Linear Variable Differential Transformers (LVDTs) attached to the lower loading head of the testing machine, as shown in Figure 3. The axial load was recorded by a load cell placed at the bottom of the testing machine. Specimens were preloaded up to $5 \%$ of the estimated load carrying capacity to prevent minor movements between the loading heads of the testing machine and the specimen, and then the load was returned to $20 \mathrm{kN}$ before starting the test. During the test, the load was applied with a displacement rate of $0.3 \mathrm{~mm} /$ minute until the resistance of the specimens dropped to $30 \%$ of the peak load, when both of concrete crashing and CFRP tube rupture occurred. The LVDTs and the load cell were connected to a data logger to record the readings every two seconds.

For eccentrically loaded specimens, the loading heads were adjusted to provide an eccentricity of $25 \mathrm{~mm}$ and $50 \mathrm{~mm}$, as shown in Figure 4. The lateral displacement was measured by using a laser triangulation that was located at the mid-height of the specimen, as shown in Figure 4. 
224 The axial load and axial deformation were recorded using the same instrumentation of concentrically loaded specimens.

226 Four specimens were tested under four-point bending. Two rigs were placed on the top and bottom of the specimens to transfer the applied load from the testing machine to the beam. The clear span between the supports was $700 \mathrm{~mm}$ and the distance between the upper point loads was $230 \mathrm{~mm}$. The typical test setup of the beam specimens is shown in Figure 5. The midspan deflection of the beam specimens was measured using laser triangulation. The loading rate and data recording were the same as column specimen testing.

\section{Experimental results and discussion}

\subsection{Failure mode}

All specimens were subjected to monotonic load until failure. Failure of unconfined HCRPC columns was evident in the gradual cracking near the mid-height of the column specimens. Spalling of the concrete cover was followed by the buckling of the longitudinal steel bars outwards. The failure of Specimen R0 after the ultimate load was sudden but not explosive under all loading conditions, because of using steel fibre within the RPC mix. The failure of this specimen was recognised by continuous concrete crack propagation at the mid-height of the concrete but the concrete cover did not spall off. For the CFRP-confined HCRPC specimens, the failure was noticed physically by the occurrence of CFRP ripples on the surface of the CFRP tube in the hoop direction followed by snapping sounds, which were heard subsequently prior to the ultimate failure due to the strap-by-strap laceration of FRP fibre within the CFRP tube due to hoop tension. Specimen CR0 experienced multi CFRP strap ruptures after the first peak was reached. These CFRP ruptures were located within the mid- 
height of the specimen, causing a fluctuation of the axial load. As the applied load increased, the ultimate load was reached with loud snapping sound of CFRP fibres laceration. A similar failure mode of Specimen CRP0 was noticed to that of Specimen CR0, but Specimen CRP0 showed less fluctuation of the axial load than Specimen CR0. With the increase of applied load, the ultimate axial load was obtained followed by very loud snapping sound of CFRP rupture. The failure mode of Specimen CS0 was characterized with multiple load snapping sounds of the CFRP rupture in the mid-height of the specimen, causing multiple peaks of the axial load in the second branch of axial load-deformation curve. In general, specimens without CFRP tube confinement showed a brittle failure in contrast with those with CFRP tube confinement that showed a ductile failure mechanism. Figures 6 and 7 show the typical failure modes of confined and unconfined HCRPC specimens, respectively.

\subsection{Hollow core RPC specimens under concentric load}

Four HCRPC column specimens of different configurations were tested under uniform concentric load until failure. Figure 8 illustrates the axial load-axial deformation behaviour of the four concentrically tested specimens.

Specimen R0 showed lower axial load and axial deformation than the CFRP-confined column specimens. The failure of this specimen was recognised by continuous concrete crack propagation at the mid-height of the concrete but the concrete cover did not spall off due to the presence of steel fibre. After carrying a load of $2986.9 \mathrm{kN}$, Specimen R0 experienced a sudden drop in the axial load, which indicates the brittle failure of this specimen. An axial deformation of $5.0 \mathrm{~mm}$ was recorded at the maximum load. The predicted axial load capacity of Specimen R0 can be calculated by using Equation (1). The predicted axial load result of Specimen R0 was $2950.8 \mathrm{kN}$ which is very close to the experimental results. 


$$
P=0.85 f_{c o}^{\prime}\left(A_{g}-A_{s}\right)+f_{y} A_{s}
$$

272

where $P$ is axial load capacity of the specimen in $\mathrm{kN}, f_{c o}^{\prime}$ is the unconfined concrete strength in $\mathrm{MPa}, A_{g}$ is the gross sectional area of concrete, $A_{s}$ is the area of longitudinal steel reinforcement, $f_{y}$ is yield stress of the longitudinal steel reinforcement.

Specimen CR0 carried a maximum axial load of $3360.2 \mathrm{kN}$ which is higher than the load carried by Specimen R0 due to CFRP tube confinement. In addition, the axial deformation of Specimen CR0 dramatically increased to $16.5 \mathrm{~mm}$ at the ultimate load. The axial load-axial deformation behaviour of Specimen CR0 consists of two parts. The first part is the linear behaviour up to the maximum axial load. Then, in the second part, the CFRP tube experienced multi CFRP strap ruptures in different locations within the mid-height of the specimen, causing axial load fluctuation. This behaviour ended with a sudden drop of axial load after the ultimate load was reached. The predicted axial load capacity of Specimen CR0 can be calculated by using Equation (2). A stress-strain model proposed by Yazici and Hadi [16], Equation (3), was adopted to calculate the axial stress of the CFRP-confined HCRPC specimens (Specimen CR0). The predicted axial load result of Specimen R0 was $2797.4 \mathrm{kN}$ which is lower than the experimental results by nearly $20 \%$.

$$
P_{n}=0.85 f_{c c}^{\prime}\left(A_{g}-A_{s}\right)+f_{y} A_{s}
$$

$$
\begin{aligned}
& K_{N}=\frac{2 E_{f} t_{f}}{D f_{c o}^{\prime}} \quad 10 \leq K_{N} \leq 20 \\
& \beta=\left(1-\frac{D_{i}^{2}}{D_{o}^{2}}\right)
\end{aligned}
$$


where, $f_{c c}^{\prime}$ is the confined concrete strength in $\mathrm{MPa}, K_{N}$ is a normalized confinement stiffness; $\beta$ is a coefficient to account for the different confinement mechanism in hollow columns; $D_{i}$ is the hollow core diameter of the concrete cylinder in $\mathrm{mm} ; D_{o}$ is the diameter of the concrete cylinder in $\mathrm{mm}$.

As shown in Figure 8, Specimen CRP0 sustained the highest values of axial load and axial deformation among the other concentrically loaded specimens. Specimen CRP0 was externally confined with the CFRP tube and internally confined with the PVC tube. The second part of the load-deformation curve showed a drop of the axial load at nearly $3400 \mathrm{kN}$ due to the rupture of some CFRP fibre within the mid-height of the tube and the rest of the CFRP fibre in the hoop direction was able to provide effective confinement to the specimen. Afterward, the loaddeformation curve experienced an ascending branch up to a maximum axial load of $3718.4 \mathrm{kN}$. For the same reason, the reading of the axial deformation continued to increase, recording 18.7 $\mathrm{mm}$ at the ultimate load. The predicted axial load capacity of Specimen CRP0 can also be calculated by using Equation (2). A model proposed by Jiang and Teng [35] showed an accurate stress-strain prediction of the CFRP-confined HCRPC specimens with inner PVC tube (Specimen CRP0). Equation (6) was suggested to model the stress-strain behaviour of Specimen CRP0. The predicted axial load result of Specimen R0 was $2847.7 \mathrm{kN}$ which underestimated the experimental results. The maximum load of the PVC tube alone was $54 \mathrm{kN}$ which is very low compared to the axial load capacity of Specimen CRP0. However, the existing of the inner PVC tube within the specimen was very effective to increase the axial load capacity of Specimen CRP0 by nearly $385 \mathrm{kN}$.

$$
\frac{f^{\prime}{ }_{c c}}{f^{\prime}{ }_{c o}}=1+3.5 \frac{f_{l}}{f^{\prime}{ }_{c o}}
$$

where, $f_{l}$ is the lateral confining pressure of the FRP tube in MPa. 
310 The axial load-axial deformation curve of Specimen CS0 showed a different behaviour in the second branch of the curve compared to other specimens. Multiple peaks of axial load can be seen along the second branch. These peaks of the axial load refer to the rupture of the CFRP straps one by one in the hoop direction. For Specimen CS0, the longitudinal steel bars and the helix were replaced with a steel tube of an equivalent axial load capacity located inside the hollow core. Thus, a maximum axial load of $3346.1 \mathrm{kN}$ was obtained by Specimen CS0, which was nearly the same maximum axial load of Specimen CR0. This is because both specimens were designed to carry the same axial load under concentric loading by replacing the ordinary steel reinforcement (longitudinal steel bars and helix) with inner steel tube. However, by using a steel cage of longitudinal bars and helix within the section of Specimen CR0, the axial load in the second branch showed less fluctuation than the axial load of Specimen CS0.

The predicted axial load capacity of Specimen CS0 can also be calculated by using Equations (2) and (6). The predicted axial load result of Specimen CS0 was $2806.4 \mathrm{kN}$ (without considering the buckling effect of the steel tube) which underestimated the experimental results. The maximum carrying load capacity of the full-length $(800 \mathrm{~mm})$ steel tube alone was $320 \mathrm{kN}$ and this reading was under the effect of steel tube buckling. By using the steel tube inside the FRP-confined concrete section, the steel tube would resist a higher axial load than the steel tube alone. This is because the fact that the surrounded concrete delays the effect of the global and the local buckling of the steel tube. The buckling effect on the axial load capacity of the steel tube can be predicted by comparing the experimental value with the predicted value of the axial load of Specimen CS0. By using the steel tube within the section of Specimen CS0, the axial load of the steel tube was increased by nearly $68 \%$ compared to the axial load of the steel tube alone. Accordingly, the existence of the inner steel tube within the specimen was effective to increase the axial load capacity of Specimen CS0 by nearly $540 \mathrm{kN}$. 
In this study, the ductility of the specimens was determined by using a method suggested by Park [36]. For this method, the equation $\mu=\Delta_{\mathrm{u}} / \Delta_{\mathrm{y}}$ was used to calculate the ductility, where $\mu$ $=$ ductility, $\Delta_{\mathrm{u}}=$ ultimate deformation and $\Delta_{\mathrm{y}}=$ yield deformation. Figure 9 explains how the yield and ultimate points are determined. The axial load, axial deformation and ductility of the specimens under concentric load are shown in Table 2.

\subsection{Hollow core RPC specimens under eccentric load}

Eight HCRPC specimens were tested under eccentric loading, the first four specimens with an eccentricity of $25 \mathrm{~mm}$ and the second four specimens with an eccentricity of $50 \mathrm{~mm}$. Figure 10 presents the axial and lateral deformation versus the axial load of the specimens subjected to a load eccentricity of $25 \mathrm{~mm}$. All the specimens that were tested under $25 \mathrm{~mm}$ eccentric load failed in compression. It can be seen from Figure 10 that the highest maximum axial load of $2290.5 \mathrm{kN}$ was sustained by Specimen CRP25. Figure 10, also shows that the maximum axial load of Specimens CR25, CRP25 and CS25 was enhanced by 7.6\%, 13.3\% and 5.5\%, respectively compared to the maximum axial load of Specimen R25 (unconfined specimen). Compared to Specimen R25, the axial deformation corresponding to the ultimate axial load was dramatically increased by $279 \%, 357 \%$ and $272 \%$ for Specimens CR25, CRP25 and CS25, respectively. Figure 10 also shows that the lateral deformations of $25 \mathrm{~mm}$ eccentric loaded specimens are higher than the axial deformations. Table 2 presents the test results of the axial load, axial and lateral deformations and ductility of specimens under $25 \mathrm{~mm}$ eccentric load.

Figure 11 illustrates the axial and lateral deformation versus the axial load of the specimens subjected to load eccentricity of $50 \mathrm{~mm}$. The highest maximum axial load of $1572.1 \mathrm{kN}$ was achieved with Specimen CRP50. Based on the test results presented in Figure 11, the maximum axial load of Specimens CR50, CRP50 and CS50 was slightly increased by 4.9\%, 
$10.8 \%$ and $2.4 \%$, respectively compared to Specimen R50 (unconfined specimen). The axial deformation corresponding to the ultimate load was significantly increased by $357 \%, 428 \%$ and $471 \%$ for Specimens CR50, CRP50 and CS50, respectively compared to Specimen R50 (unconfined specimen). The test results of the load, axial and lateral deformations and ductility of specimens tested under $50 \mathrm{~mm}$ eccentric load are presented in Table 2.

Compared to the specimens in Group R, the maximum axial load of specimens in Groups CR, CRP, and CS was observed to decrease with the increase of loading eccentricity. On the other hand, the axial deformation capacity of specimens in Groups CR, CRP, and CS was observed to increase dramatically by increasing the load eccentricity. Thus, higher values of ductility were achieved by $50 \mathrm{~mm}$ eccentric loaded specimens compared to those specimens tested under $25 \mathrm{~mm}$ eccentricity, as shown in Table 2.

\subsection{Hollow core RPC specimens under flexural loading}

In order to determine the maximum bending moment of the HCRPC specimens, a flexural test was performed under a four-point bending system. The dimensions of the HCRPC beam specimens were kept the same as the column specimens tested under concentric and eccentric loading for consistency reasons. In this case, the shear span-depth ratio of the beam specimen was less than 1.5; however, the presence of the $1.5 \mathrm{~mm}$ thick CFRP confinement and the steel helix had prevented the shear failure to occur in these beams, as shown in Figures 6 and 7. Figure 12 shows the load versus midspan deflection curves of the four specimens. According to this figure, the highest values of load, corresponding midspan deflection and ductility were achieved by Specimen CRPB. In comparison with Specimen RB (unconfined specimen), the maximum load of Specimens CRB, CRPB and CSB were increased by $133.1 \%, 138.5 \%$ and $78.4 \%$, respectively. These increments were due to the effect of the longitudinal FRP fibres 
within the CFRP tube that significantly enhances the load carrying capacity and ductility of the specimens. Table 2 presents the test results of the four beam specimens, including the values of load, midspan deflection and ductility. These values were calculated with the same methods as these used above for concentrically and eccentrically loaded specimens.

\subsection{Effect of CFRP tube confinement}

The effect of the external confinement of the CFRP tube on the strength and ductility of HCRPC specimens was experimentally investigated by comparing test results obtained from the specimens of Groups R and CR. Figure 13 shows the normalized values of maximum axial load and ductility of specimens in Group CR with respect to the ones in Group R. For concentrically loaded specimen, the maximum axial load and ductility of Specimen CR0 were increased by $12.5 \%$ and $198 \%$, respectively compared to Specimen R0 (unconfined column).

For eccentrically loaded specimens, the maximum axial load of Specimens CR25 and CR50 was increased by $7.6 \%$ and $7.5 \%$, respectively compared to the corresponding unconfined specimens. In addition, the ductility of Specimens CR25 and CR50 was also increased by $200 \%$ and $328 \%$, respectively. For flexural loading, the CFRP layer in the longitudinal direction has a significant influence on the maximum load and ductility of the specimen. The maximum load and the ductility of Specimen CRB increased by $69 \%$ and $42 \%$, respectively compared to the corresponding unconfined specimens.

Based on the test results presented in Figure 13, it can be seen that the use of CFRP tube can significantly increase the ductility of HCRPC specimens but the maximum load of the confined specimen increased slightly due to the existence of the inner hole. 


\subsection{Effect of internal confinement with PVC tube}

406 The effect of using PVC tubes for inner confinement on the strength and ductility of HCRPC

407 specimens can be ascertained by comparing the test results of specimens in Group CR and 408 Group CRP. Figure 14 shows the normalized values of maximum axial load and ductility of the 409 specimens in Group CRP with respect to those in Group CR. In terms of maximum axial load and under concentric loading, Specimen CRP0 showed an increase of $10.1 \%$ compared to Specimen CR0. It can be seen from Figure 8 that the second branch of the load-deformation curve of Specimen CRP0 experienced an ascending behaviour because of the internal confinement provided by the PVC tube. The maximum axial load was also slightly higher for Group CRP than Group CR under $25 \mathrm{~mm}, 50 \mathrm{~mm}$ eccentric loading. Figure 14 shows the normalized maximum axial load and normalized ductility of the specimens in Group CR and Group CRP under different loading conditions. According to this figure, the ductility of Specimens CRP0, CRP25, CRP50 and CRPB was increased by $42 \%, 37 \%, 24 \%$ and $6 \%$ compared to Specimens CR0, CR25, CR50 and CRB, respectively. These findings indicate that introducing PVC tube in HCRPC specimens for internal confinement can slightly enhanced the strength but the ductility was dramatically improved for this type of structural members. The PVC tube was made of a very low stiffness material and it is not expected to improve the strength of HCRPC specimens. On the other hand, the concrete close to the inner edge of the HCRPC specimens experiences a lack of load resistance due to surface concrete spalling [20]. Thus, by using PVC tube an additional internal pressure can be applied to the surrounding concrete that improves the confinement efficiency and thus further improves the ductility of HCRPC specimens. 


\subsection{Effect of replacing normal steel reinforcement with steel tube}

430 The effect of using steel tube as an alternative to the conventional steel reinforcement in HCRPC specimens was investigated by comparing the experimental results of the specimens in Group CR and Group CS. Figure 15 shows the normalized values of maximum axial load and ductility of the specimens in Group CS with respect to those in Group CR. In the column design of Group CS, the steel tube was selected to obtain an equivalent axial load to the steel bars that were used in the columns design of Group R.

As expected from the design of Specimens CRB and CSB, the test results showed that the maximum axial load was nearly the same under concentric and eccentric loading conditions but under flexural loading, Specimen CRB showed higher maximum load than Specimen CSB as the tensile reinforcement of Specimen CSB was located away from the centre of the specimen.

Figure 8 shows the load-deformation curves of specimens CR0 and CS0. For concentrically loaded specimens, Specimen CR0 showed less fluctuation of load-deformation behaviour post the yield load than Specimen CS. It is well known that the concrete exhibits a non-uniform lateral expansion under applied axial compression. In FRP-confined concrete specimens, the non-uniform expansion leads to non-uniform lateral pressure towards the surrounded FRP confinement along the full height of the concrete specimen. This behaviour is more noticeable in the RPC specimens due the brittle failure of the concrete. For Specimen CR0, the presence of the steel bar and helix within the concrete section may provide an additional confinement to the concrete that reduces the applied lateral pressure on the outer CFRP tube. On the other hand, the presence of the inner steel tube within the section of Specimen CS0 provides an 450 internal confinement and additional pressure toward the annular concrete and the surrounding CFRP tube which may cause the fluctuation in the second branch of the load-deformation curve. 
$454 \quad 3.8$. Experimental axial load-bending moment interaction diagrams

455 For a column's cross-section, the $P-M$ interaction diagram shows the maximum axial load and 456 the corresponding bending moment that can be applied on that cross-section. This means any 457 loading combination of axial load and bending moment outside the $P-M$ envelope is not 458 accepted. In this section, experimental and analytical procedures were adopted to create $P-M$ 459 interaction diagrams for each group of the HCRPC specimens.

The experimental $P-M$ interaction diagrams of Groups R, CR, CRP and CS were created based on the test results of specimens tested under loading conditions of concentric, $25 \mathrm{~mm}$ eccentricity, $50 \mathrm{~mm}$ eccentricity and four-point bending. Each experimental $P-M$ curve was constructed using four points, including a point corresponding to pure bending. The maximum axial load was identified as the highest value of axial load carried by the specimen before the rupture of CFRP tube was reached. The corresponding bending moment at the maximum axial load consists of primary and secondary moments. The primary moment was caused by the eccentricity of the applied load, whereas the secondary moment was caused by the lateral deformation corresponding to the maximum axial load.

For specimens tested under concentric loading condition, the value of the corresponding bending moment $(M)$ is zero. For specimens tested under $25 \mathrm{~mm}$ and $50 \mathrm{~mm}$ eccentricity, the value of the corresponding bending moment $(M)$ was calculated using Equation 7.

$$
M=M_{1}+M_{2}=P e_{\text {exp. }}+P \delta
$$

472 where, $M_{1}, M_{2}$ are the primary and secondary bending moments, respectively; $P$ is the applied 473 axial load; $e_{\text {exp }}$. is the experimental eccentricity of loading; $\delta$ is the lateral deformation corresponding to the maximum axial load. 
475 For specimens tested under four-point bending, Equation 8 was used to calculate the value of 476 the bending moment.

$$
M=\frac{P L}{6}
$$

477 where, $L$ is the clear span length of the specimens under four-point bending which was $700 \mathrm{~mm}$ 478 in this study.

The experimental $P-M$ interaction diagrams of Groups R, CR, CRP and CS are shown in Figure 16. For concentrically loaded specimens, Groups CR, CRP and CS carried an axial load of $12.5 \%, 24.5 \%$ and $12 \%$, respectively larger than the axial load of Group R. By increasing the eccentricity to $25 \mathrm{~mm}$, Groups CR, CRP and CS resisted an axial load of $7.6 \%, 13.3 \%$ and $11.1 \%$ higher than the axial load of Group R and the bending moment of Groups CR, CRP and CS also increased by $21.3 \%, 29.4 \%$ and $26.9 \%$, respectively compared to the bending moment of Group R.

For HCRPC specimens that were subjected to $50 \mathrm{~mm}$ eccentricity, Groups CR, CRP and CS showed $6.6 \%, 10.8 \%$ and $2.3 \%$ higher axial load than axial load of Group R, respectively and the corresponding bending moments were increased by $3.6 \%, 10.8 \%$ and $3.8 \%$, respectively compared to the bending moment of Group R. It should be mentioned that Group R showed a higher bending moment than the actual one under $50 \mathrm{~mm}$ eccentric load because of an overestimation of the secondary moment $\left(M_{2}\right)$. The reason behind this misleading calculation is that the lateral deformation reading $(\delta)$ of the laser triangulation device was taken from fully cracked concrete cover instead of the surface of the concrete cover.

For specimens tested under four-point bending, Groups CR, CRP and CS resisted bending 495 moment of $133 \%, 138 \%$ and $78 \%$ larger than the bending moment of Group R, respectively. 
496 In the four-point bending tests, it can be seen from the results in Figure 16 that Groups CR and

497 CS showed different values of bending moment, although they had been designed to resist the

498

499

500

501

502

503

504

505

506

507

508

509

510

511

512

513

514

515

516

517 same axial load. The reason behind that was lack of the bond between the RPC and the internal steel tube that reduced the transferred load from the RPC to the steel tube. In addition, in the design of Group CR, the longitudinal steel bars are located to obtain higher bending moment than Group CS that had the internal steel tube located in the centre of the specimen's crosssection.

In general, the test results presented in Figure 12 clearly shows that Group CRP exhibited larger capacity of axial load-bending moment interaction diagram than the other groups in this study.

\section{Conclusions}

This study has presented the experimental test results of sixteen specimens that explain the behaviour of HCRPC specimens with and without CFRP tube confinement in different configurations. These specimens were tested under concentric load, $25 \mathrm{~mm}$ eccentric load, 50 $\mathrm{mm}$ eccentric load and four-point bending. The test results involved the interpretation of the failure mode, axial load versus axial and lateral deformation behaviour and the ductility of the specimens. Based on the experimental test results presented above, the following conclusions can be drawn:

1. By introducing CFRP tube confinement, the strength of HCRPC specimens was slightly increased, whereas the ductility was significantly improved.

2. By providing an inner PVC tube to the HCRPC specimens, which are internally reinforced with conventional steel reinforcement and externally confined with a CFRP 
tube, the strength was slightly enhanced but the ductility was dramatically improved. This is because of the beneficial effect of the PVC tube that provides an additional inner confinement to the annular concrete section. In addition, the experimental results showed that the HCRPC specimens with an inner PVC tube exhibit larger capacity of axial loadbending moment interaction diagram than the other types of specimens in this study.

3. By replacing the conventional steel reinforcement with an equivalent steel tube within the section of HCRPC specimens, the values of strength and ductility are nearly the same. However, under flexural loading, a better performance of HCRPC specimen with normal steel reinforcement can be achieved than the one with the steel tube. These results also indicate that the bond between the steel tube and the surrounded concrete should be enhanced to improve the flexural capacity of the HCRPC with inner steel tube.

4. By increasing the eccentricity of loading, the axial load capacity of all HCRPC specimens experienced a significant reduction as expected. This reduction was nearly the same in all groups of HCRPC specimens. In contrast with the unconfined HCRPC specimens, the ultimate axial deformation of the CFRP-confined HCRPC specimens was observed to increase dramatically with the increase of loading eccentricity. Thus, higher values of ductility were achieved by the CFRP-confined HCRPC specimens compared to those unconfined HCRPC specimens.

5. The axial load capacity of the HCRPC can be reasonably predicted using the available concrete stress-strain model.

6. The four-point bending test indicates that the use of a CFRP tube can significantly increase the maximum load and ductility of HCRPC specimens. 


\section{Acknowledgement}

543 The authors would like to thank Messers Fernando Escribano, Duncan Best and Ritchie 544 Mclean, technical staff at the High Bay Laboratory of the School of Civil, Mining and 545 Environmental Engineering, University of Wollongong, Australia, who provided the technical 546 support during the tests. The second author is grateful for the financial support received from 547 the Higher Committee for Education Development in Iraq.

\section{References}

550 [1] P. Richard, M. Cheyrezy. Composition of reactive powder concretes. Cement and Concrete Research, 25(7) (1995) 1501-1511.

552 [2] A.Z. Fam, S.H. Rizkalla. Behaviour of axially loaded concrete-filled circular fibrereinforced polymer tubes. ACI Structural Journal, 98(3) (2001) 451-461.

554 [3] Mirmiran. Stay-in-place FRP form for concrete columns. Advances in Structural Engineering, 6(3) (2003) 231-41.

[4] R. Burgueno, A. Davol, L. Zhao, F. Seible, V.M. Karbhari. Flexural behaviour of hybrid fibre-reinforced polymer/concrete beam/slab bridge component. ACI Structural Journal, 101(2) (2004) 228-236.

559 [5] Fam, D. Schnerch, S. Rizkalla. Rectangular filament-wound glass fibre reinforced polymer tubes filled with concrete under flexural and axial loading: experimental investigation. Journal of Composites for Construction, 9(1) (2005) 25-33. 
[6] H.M. Mohamed, R. Masmoudi. Flexural strength and behaviour of steel and FRP reinforced concrete-filled FRP tube beams. Engineering Structures, 32(11) (2010) 37893800 .

[7] K.S. Youm, J.Y. Cho, Y.H. Lee, J.J. Kim. Seismic performance of modular columns made of concrete filled FRP tubes. Engineering Structures, 57 (2013) 37-50.

[8] M.N.S. Hadi, Q.S. Khan, N.M. Sheikh. Axial and flexural behaviour of unreinforced and FRP bar reinforced circular concrete filled FRP tube columns. Construction and Building Materials, 122 (2016) 43-53.

[9] Y. Zhou, X. Liu, F. Xing, H. Cui, L. Sui. Axial compressive behaviour of FRP-confined lightweight aggregate concrete: An experimental study and stress-strain relation model. Construction and Building Materials, 119 (2016) 1-15.

[10] S. Raffoul, R. Garcia, D. E. Margarit, M. Guadagnini, I. Hajirasouliha, K. Pilakoutas. Behaviour of unconfined and FRP-confined rubberised concrete in axial compression. Construction and Building Materials, 147 (2017) 388-397.

[11] J. Wang, P. Feng, T. Hao, Q. Yue. Axial compressive behaviour of seawater coral aggregate concrete-filled FRP tubes. Construction and Building Materials, 147 (2017) $272-285$.

[12] R. Modarelli, F. Micelli, O. Manni. FRP-confinement of hollow concrete cylinders and prisms. ACI Special Publications, 230 (58) (2005), 1029-1046.

[13] G.P. Lignola, A. Prota, G. Manfredi, E. Cosenza. Unified theory for confinement of RC solid and hollow circular columns. Composites Part B: Engineering, 39(7-8) (2005) 1151-1160. 
[14] V. Yazici, M.N.S. Hadi. Axial load-bending moment diagrams of carbon FRP wrapped hollow core reinforced concrete columns. Journal of Composites for Construction, 13 (4) (2009) 262-268.

[15] Y. Kusumawardaningsih, M.N.S. Hadi. Comparative behaviour of hollow columns confined with FRP composites. Composite Structures, 93 (2010) 198-205.

[16] V. Yazici, M.N.S. Hadi. Normalized confinement stiffness approach for modelling FRPconfined concrete. Journal of Composites for Construction, 16(5) (2012) 520-528.

[17] M.N.S. Hadi, T.D. Le. Behaviour of hollow core square reinforced concrete columns wrapped with CFRP with different fibre orientations. Construction and Building Materials, 50 (2014) 62-73.

[18] J.G. Teng, T. Yu, Y.L. Wong, S.L. Dong, Hybrid FRP concrete steel tubular columns: Concept and behaviour. Construction and Building Materials, 21(4) (2007) 846-854.

[19] T. Yu, Y.L. Wong, J.G. Teng, S.L. Dong. Flexural behaviour of hybrid FRP-concretesteel double-skin tubular members. Journal of Composites for Construction, 10(5) (2006) 443-452.

[20] Y.L. Wong, T. Yu, J.G. Teng, S.L. Dong. Behaviour of FRP-confined concrete in annular section columns. Composites Part B: Engineering, 39 (2008) 451-466.

[21] T. Yu, J.G. Teng, Y.L. Wong, S.L. Dong, Finite element modelling of confined concreteI: Drucker-Prager type plasticity model, Engineering Structures, 32(3) (2010a) 665-79.

[22] T. Yu, J.G. Teng, Y.L. Wong, Stress-strain behaviour of concrete in hybrid double-skin tubular columns. Journal of Structural Engineering, 136(4) (2010b) 379-389. 
[23] T. Yu, J.G. Teng, Behaviour of hybrid FRP-concrete-steel double-skin tubular columns with a square outer tube and a circular inner tube subjected to axial compression. Journal of Composites for Construction, 17(2) (2013) 271-279.

[24] AS 3600-2009, Concrete structure, Australian Standard, Sydney, NSW, 2009.

[25] AS1012.9-1999, Methods of Testing Concrete, Method 9: Determination of the Compressive Strength of Concrete Specimens, Australian Standard, Sydney, NSW, 1999.
[26] Ganzhou
Daye Metallic Fibres
Co. 2015
[cited
2016; http://www.gzdymf.com/product/WSF_Steel_Fibre.html].

[27] H.A. Goaiz, T. Yu, M.N.S. Hadi. Quality Evaluation Tests for Tensile Strength of Reactive Powder Concrete. Journal of Materials in Civil Engineering, 30(5) (2018) 04018070.

[28] ASTM C494/ C494-15, Standard Specification for Chemical Admixtures for Concrete, American Society for Testing and Materials, 100 Barr Harbor Drive, PO Box C700, West Conshohocken, PA19428-2959, United States, 2015.

[29] ASTM C230/C230M-14, Standard Specification for Flow Table for Use in Tests of Hydraulic Cement, American Society for Testing and Materials, 100 Barr Harbor Drive, PO Box C700, West Conshohocken, PA19428-2959, United States, 2014.

[30] CST Composites. 2015 [cited 2015; http://www.cstcomposites.com/].

[31] ASTM D3039/D3039-14, Standard Test Method for Tensile Properties of Polymer Matrix Composite Materials, 100 Barr Harbor Drive, PO Box C700, West Conshohocken, PA19428-2959, United States, 2014. 
626

627

628

629

630

631

632

633

634

635

636

637

638

639

640

641

642

643

644

645

646

647

\section{9}

[32] ASTM D2290/D2290-12, Standard Test Method for Apparent Hoop Tensile Strength of Plastic or Reinforced Plastic Pipe, 100 Barr Harbor Drive, PO Box C700, West Conshohocken, PA19428-2959, United States, 2012.

[33] ASTM D638/ASTM D638-14, Standard Test Method for Tensile Properties of Plastics, 100 Barr Harbor Drive, PO Box C700, West Conshohocken, PA19428-2959, United States, 2014.

[34] AS1391-2007, Metallic Materials-Tensile Testing at Ambient Temperature, Australian Standard, Sydney, NSW, 2007.

[35] T. Jiang, J.G. Teng. Analysis-oriented stress-strain models for FRP-confined concrete. Engineering Structures, 29 (2007) 2968-2986.

[36] R. Park. Evaluation of ductility of structures and structural assemblages from laboratory testing. Bulletin New Zealand National Society for Earthquake Engineering, 22(3) (1989) 155-66.

40 
648

$649 \quad$ List of Tables

650 Table 1 Main test matrix.

651 Table 2 Experimental results of test specimens.

652

653

654

655

656

657

658

659

660

661

662

663

664

665

666

667

668

669

670 


\section{List of Figures}

672 Figure 1 Cross-section details of HCRPC specimens

673 Figure 2 Typical tensile stress-strain behaviour and dimensions of PVC coupons.

674 Figure 3 Typical setup of concentric loading test.

675 Figure 4 Typical setup of eccentric loading test.

676 Figure 5 Typical setup of four-point bending testing.

677 Figure 6 Typical failure modes of unconfined HCRPC specimens.

678 Figure 7 Typical failure modes of CFRP-confined HCRPC specimens.

679 Figure 8 Axial load-deflection diagrams of concentrically tested column specimens.

680 Figure 9 Definitions for yield and ultimate deformation (a) drop after yield; (b) softening after 681 yield; (c) hardening after yield.

682 Figure 10 Axial load-deflection diagrams for column specimens tested under $25 \mathrm{~mm}$ 683 eccentricity.

684 Figure 11 Axial load-deflection diagrams for column specimens tested under $50 \mathrm{~mm}$ 685 eccentricity.

686 Figure 12 Load-midspan deflection diagrams for beam specimens tested under four-point 687 bending.

688 Figure 13 Effect of CFRP tube confinement on the maximum load and ductility of HCRPC 689 specimens.

690 Figure 14 Effect of inner PVC tube on the maximum load and ductility of CFRP-confined 691 HCRPC specimens.

692 Figure 15 Effect of replacing normal steel reinforcement with steel tube on the maximum load 693 and ductility of CFRP-confined HCRPC specimens

694 Figure 16 Experimental P-M interaction diagrams of all HCRPC specimens 
Table 1 Main test matrix

697

\begin{tabular}{|c|c|c|c|c|c|}
\hline \multirow{2}{*}{$\begin{array}{l}\text { Specimen } \\
\text { label }\end{array}$} & \multirow{2}{*}{$\begin{array}{c}\text { Outer CFRP } \\
\text { tube }\end{array}$} & \multirow[b]{2}{*}{ Inner tube } & \multicolumn{2}{|c|}{ Internal reinforcement } & \multirow{2}{*}{$\begin{array}{c}\text { Test } \\
\text { eccentricity } \\
(\mathrm{mm})\end{array}$} \\
\hline & & & $\begin{array}{l}\text { Longitudinal } \\
\text { Steel }\end{array}$ & Helix & \\
\hline R0 & \multirow{4}{*}{--- } & \multirow{4}{*}{---- } & $6 \mathrm{~N} 12$ & R10@50 mm & 0 \\
\hline R25 & & & $6 \mathrm{~N} 12$ & R10@50 mm & 25 \\
\hline R50 & & & $6 \mathrm{~N} 12$ & R10@50 mm & 50 \\
\hline $\mathrm{RB}$ & & & $6 \mathrm{~N} 12$ & R10@50 mm & Bending \\
\hline CR0 & \multirow{4}{*}{$\begin{array}{c}206 \mathrm{~mm} \text { inner } \\
\text { Diameter } \times 1.5 \\
\mathrm{~mm} \text { wall } \\
\text { thickness }\end{array}$} & \multirow{4}{*}{----} & $6 \mathrm{~N} 12$ & R10@50 mm & 0 \\
\hline CR25 & & & $6 \mathrm{~N} 12$ & R10@50 mm & 25 \\
\hline CR50 & & & $6 \mathrm{~N} 12$ & R10@50 mm & 50 \\
\hline CRB & & & $6 \mathrm{~N} 12$ & $\mathrm{R} 10 @ 50 \mathrm{~mm}$ & Bending \\
\hline CRP0 & \multirow{4}{*}{$\begin{array}{c}206 \mathrm{~mm} \text { inner } \\
\text { Diameter } \times 1.5 \\
\text { mm wall } \\
\text { thickness }\end{array}$} & \multirow{4}{*}{$\begin{array}{l}\text { PVC of } 90 \mathrm{~mm} \\
\text { outer Diameter } \\
\times 3.5 \mathrm{~mm} \text { wall } \\
\text { thickness }\end{array}$} & $6 \mathrm{~N} 12$ & R10@50 mm & 0 \\
\hline CRP25 & & & $6 \mathrm{~N} 12$ & $\mathrm{R} 10 @ 50 \mathrm{~mm}$ & 25 \\
\hline CRP50 & & & $6 \mathrm{~N} 12$ & R10@50 mm & 50 \\
\hline CRPB & & & $6 \mathrm{~N} 12$ & $\mathrm{R} 10 @ 50 \mathrm{~mm}$ & Bending \\
\hline CS0 & \multirow{4}{*}{$\begin{array}{c}206 \mathrm{~mm} \text { inner } \\
\text { Diameter } \times 1.5 \\
\text { mm wall } \\
\text { thickness }\end{array}$} & \multirow{4}{*}{$\begin{array}{l}\text { Steel of } 90 \mathrm{~mm} \\
\text { outer Diameter } \\
\times 3.5 \mathrm{~mm} \text { wall } \\
\text { thickness }\end{array}$} & --- & --- & 0 \\
\hline $\mathrm{CS} 25$ & & & --- & --- & 25 \\
\hline CS50 & & & --- & $-\overline{---}$ & 50 \\
\hline CSB & & & --- & ---- & Bending \\
\hline
\end{tabular}


Table 2 Experimental results of test specimens

\begin{tabular}{|c|c|c|c|c|}
\hline Column specimen tested under concentric load & R0 & CR0 & CRP0 & CS0 \\
\hline Maximum load (kN) & 2986.9 & 3360.2 & 3717.4 & 3346.1 \\
\hline Axial deformation at maximum load (mm) & 5.0 & 11.8 & 17.7 & 11.0 \\
\hline Yield load $(\mathrm{kN})$ & 2645.6 & 2849.0 & 2976.1 & 2744.7 \\
\hline Axial deformation at yield load (mm) & 3.7 & 4.3 & 4.7 & 4.0 \\
\hline Ultimate axial deformation (mm) & 5.0 & 16.5 & 18.7 & 15.9 \\
\hline Ductility & 1.29 & 3.84 & 5.45 & 3.63 \\
\hline Column specimen tested under $25 \mathrm{~mm}$ eccentricity & $\mathrm{R} 25$ & CR25 & CRP25 & $\mathrm{CS} 25$ \\
\hline Maximum load $(\mathrm{kN})$ & 2021.5 & 2176 & 2290.5 & 2132.6 \\
\hline Axial deformation at maximum load (mm) & 4.7 & 5.4 & 7.5 & 6.1 \\
\hline Lateral deformation at max. load (mm) & 2.7 & 6.27 & 6.7 & 3.69 \\
\hline Yield load $(\mathrm{kN})$ & 1768.3 & 2051.7 & 2119.4 & 2018.6 \\
\hline Axial deformation at yield load (mm) & 3.9 & 4.6 & 5.0 & 4.2 \\
\hline Lateral deformation at yield load $(\mathrm{mm})$ & 2.0 & 2.8 & 3.7 & 2.9 \\
\hline Ultimate axial deformation $(\mathrm{mm})$ & 4.9 & 18.3 & 22.4 & 18.6 \\
\hline Ultimate lateral deformation $(\mathrm{mm})$ & 2.7 & 33.7 & 38.9 & 25.4 \\
\hline Ductility & 1.34 & 4.01 & 5.48 & 4.31 \\
\hline Column specimen tested under $50 \mathrm{~mm}$ eccentricity & R50 & CR50 & CRP50 & CS50 \\
\hline Maximum load (kN) & 1418.9 & 1488.2 & 1572.1 & 1452.3 \\
\hline Axial deformation at maximum load (mm) & 4.2 & 6.7 & 4.5 & 5.2 \\
\hline Lateral deformation at max. load $(\mathrm{mm})$ & 4.1 & 2.5 & 6.4 & 2.8 \\
\hline Yield load $(\mathrm{kN})$ & 1236.5 & 1378.9 & 1521.1 & 1401.7 \\
\hline Axial deformation at yield load (mm) & 3.9 & 4.1 & 4.3 & 4.7 \\
\hline Lateral deformation at yield load (mm) & 3.2 & 2.1 & 5.3 & 2.3 \\
\hline Ultimate axial deformation $(\mathrm{mm})$ & 4.2 & 20.5 & 25.2 & 23.5 \\
\hline Ultimate lateral deformation $(\mathrm{mm})$ & 4.1 & 35.5 & 32.1 & 27.8 \\
\hline Ductility & 1.10 & 4.71 & 5.82 & 5.15 \\
\hline Beam specimen & RB & CRB & CRPB & CSB \\
\hline Maximum load $(\mathrm{kN})$ & 340.0 & 792.7 & 811.0 & 606.4 \\
\hline Midspan deflection at maximum load (mm) & 7.2 & 27.2 & 29.9 & 23.8 \\
\hline Yield load $(\mathrm{kN})$ & 284.6 & 579.7 & 651.6 & 443.4 \\
\hline Midspan deflection at yield load (mm) & 4.3 & 6.4 & 5.5 & 4.9 \\
\hline Ultimate midspan deflection $(\mathrm{mm})$ & 15.8 & 30.0 & 32.3 & 24.8 \\
\hline Ductility & 3.33 & 6.22 & 6.60 & 4.21 \\
\hline
\end{tabular}




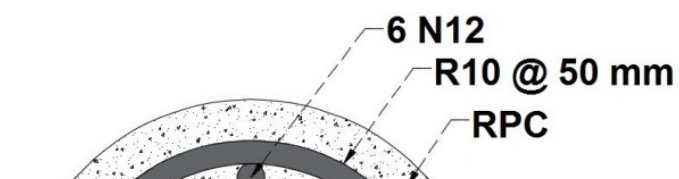

704

705

706

707

708

709

710

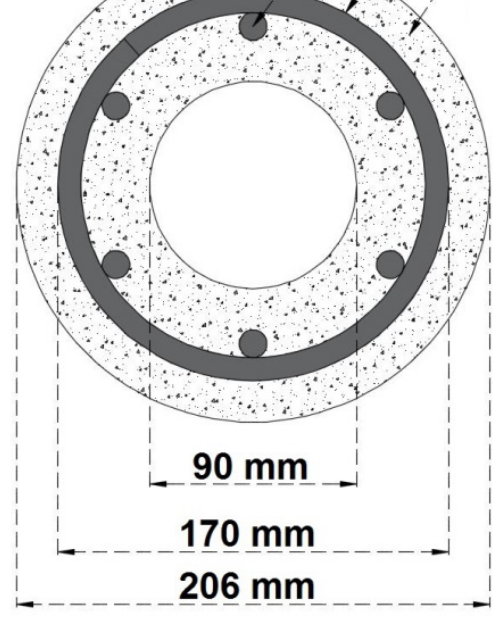

Group R

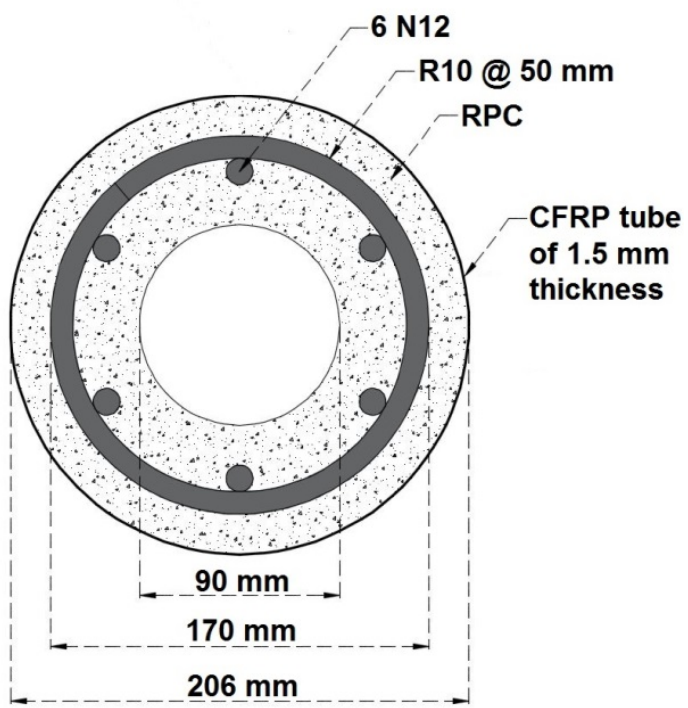

Group CR

711

712
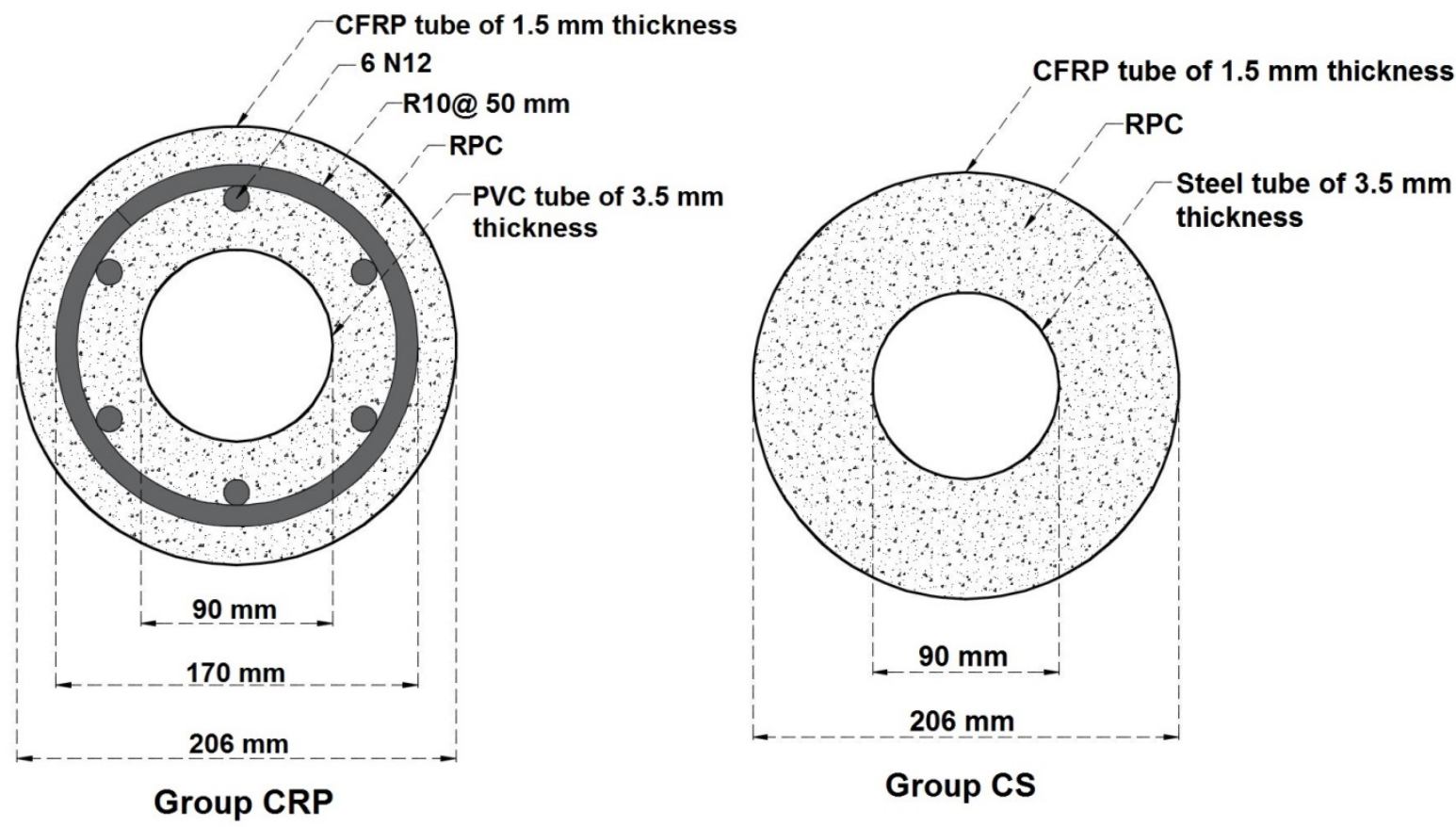

722

723

Figure 1 Cross-section details of HCRPC specimens 


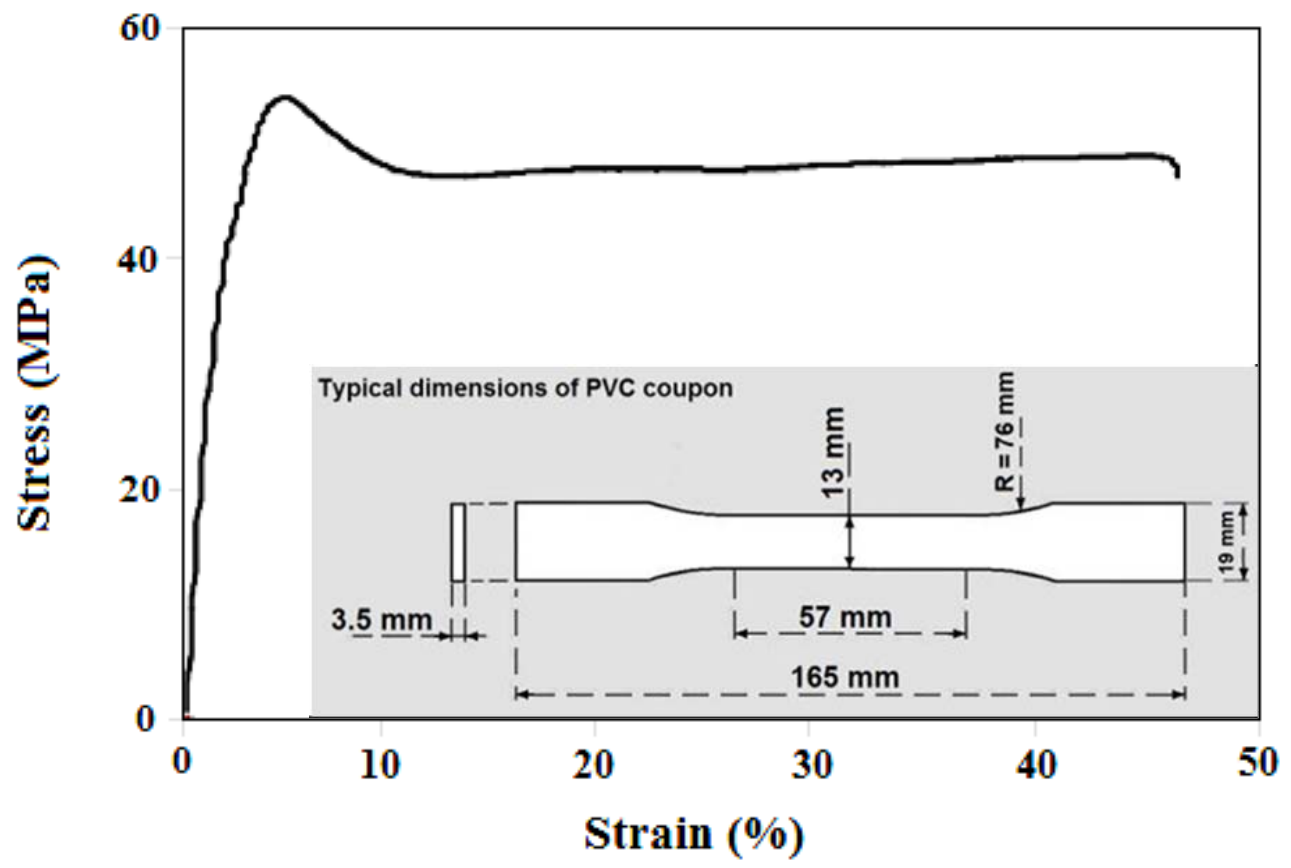

Figure 2 Typical tensile stress-strain behaviour and dimensions of PVC coupons 


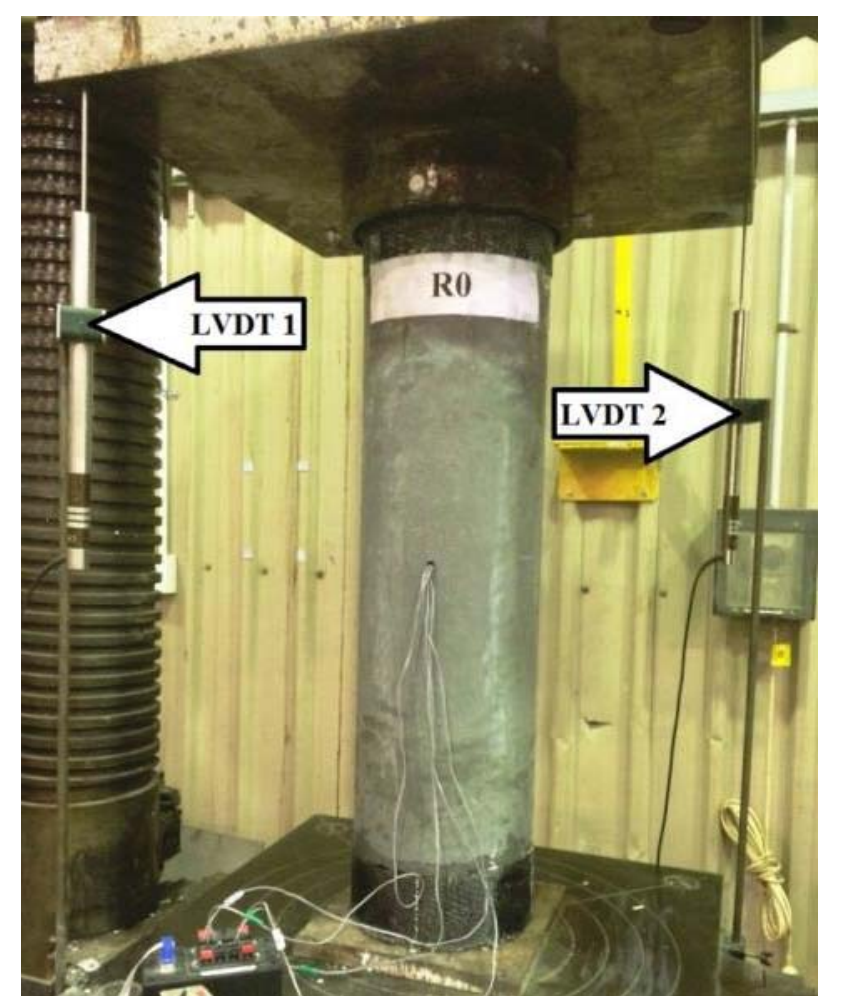

Figure 3 Typical setup of concentric loading test 

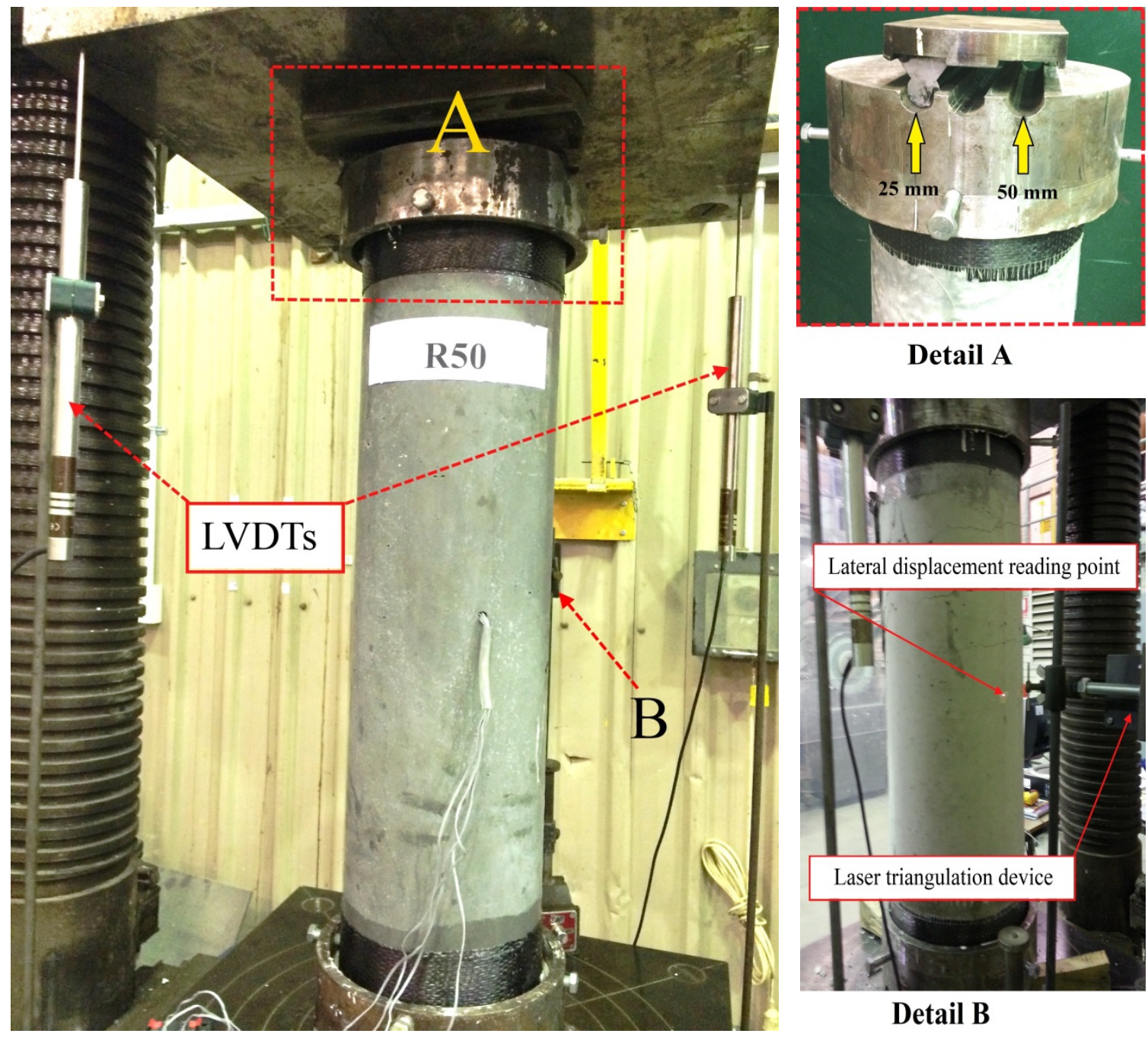

Detail A

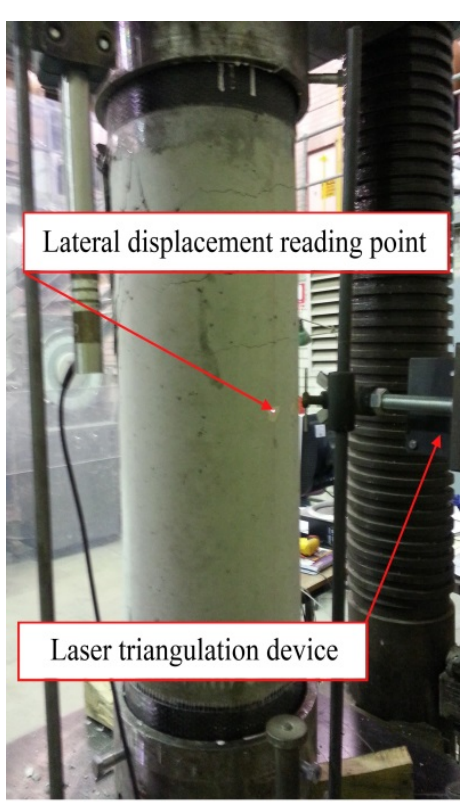

Detail B

Figure 4 Typical setup of eccentric loading test 


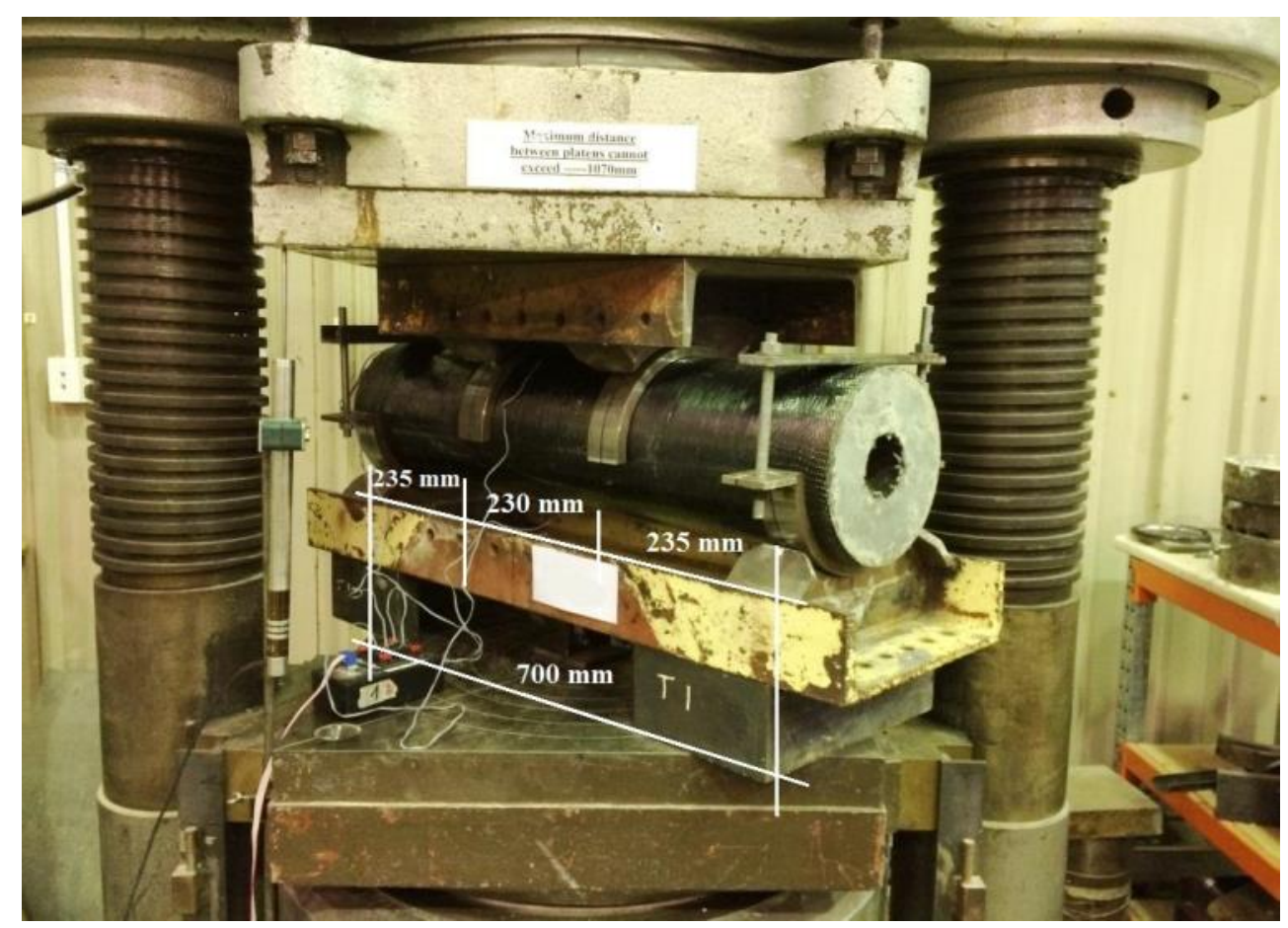

Figure 5 Typical setup of four-point bending testing 


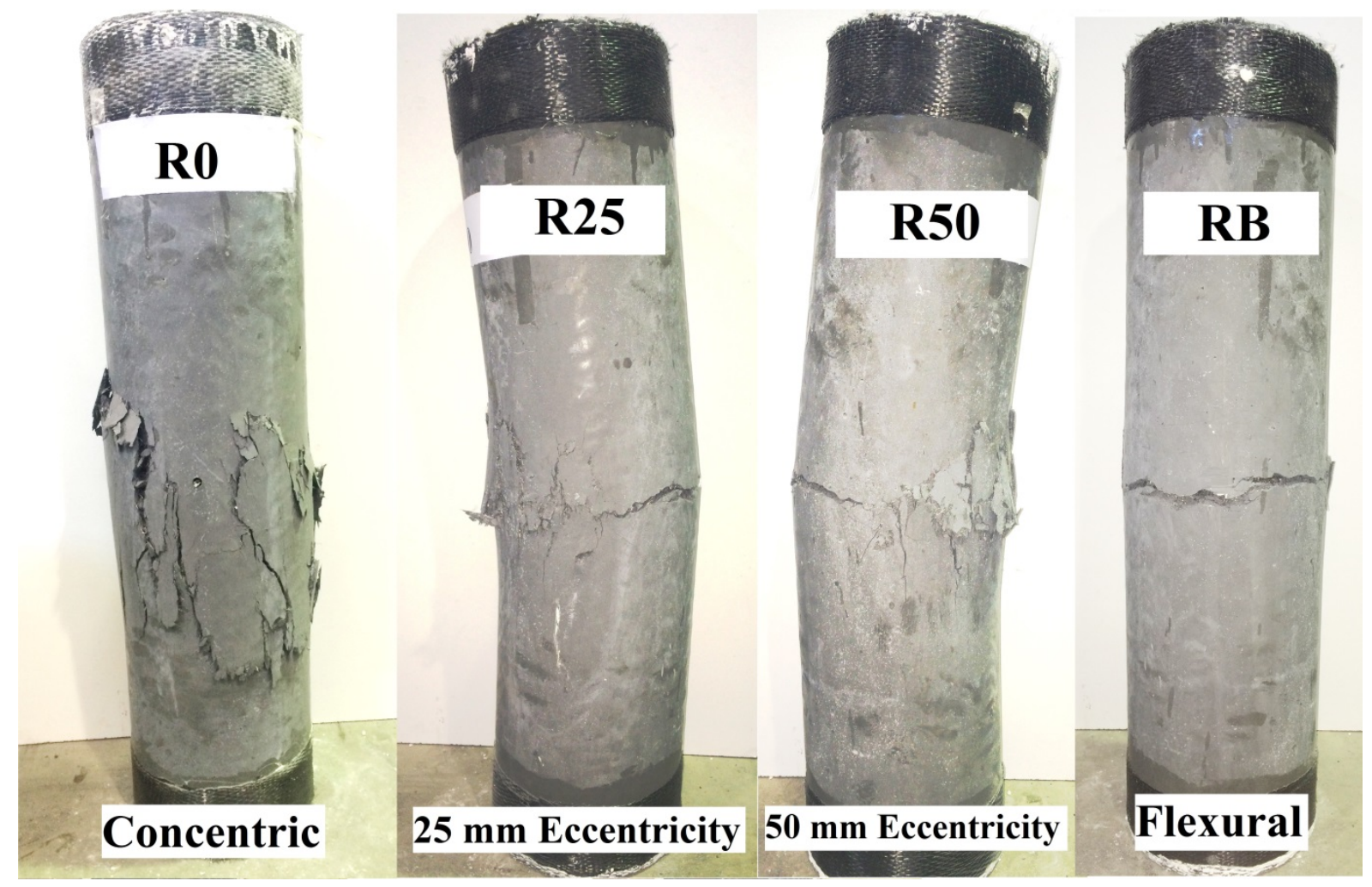

Figure 6 Typical failure modes of unconfined HCRPC specimens 


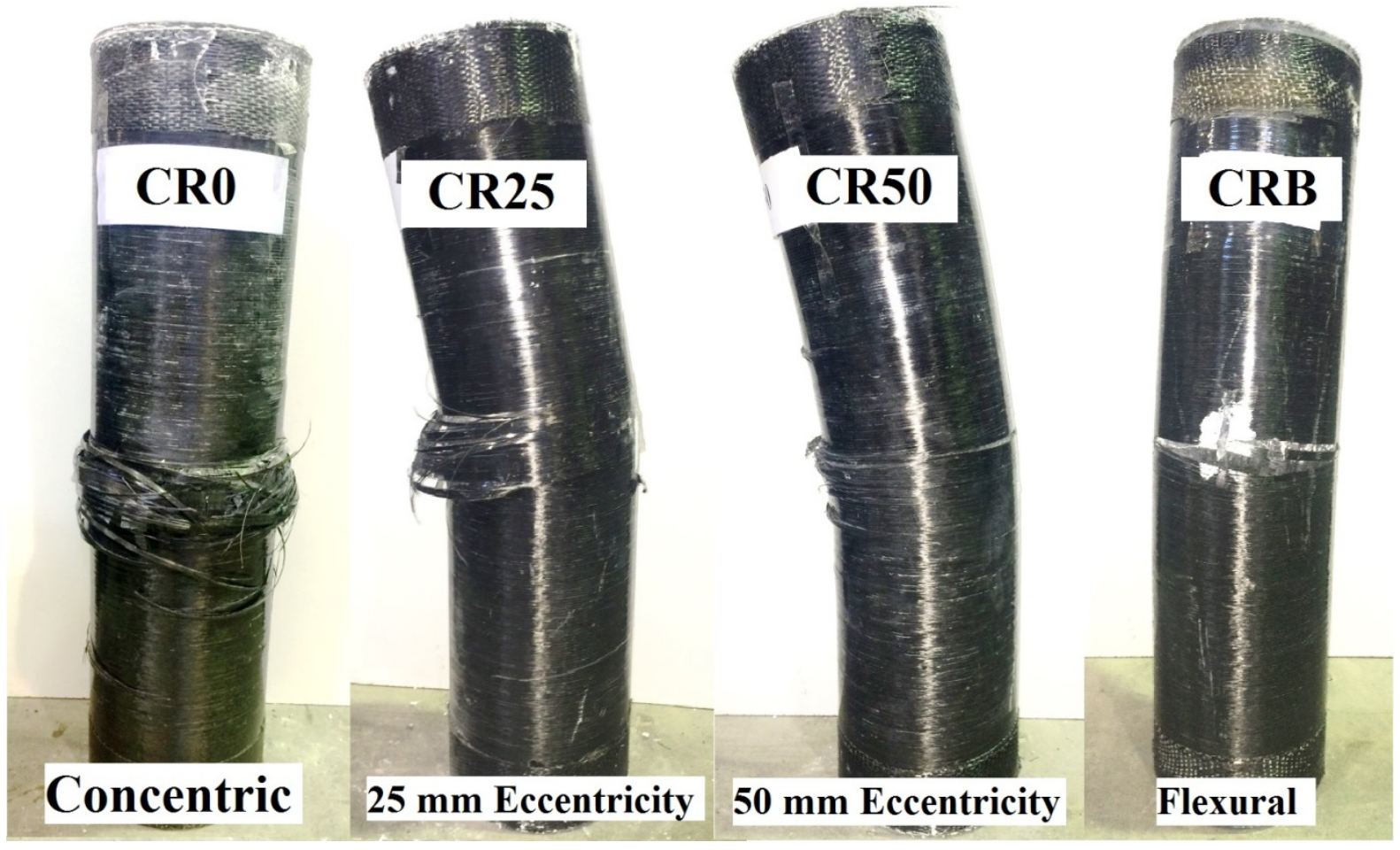

Figure 7 Typical failure modes of CFRP-confined HCRPC specimens 


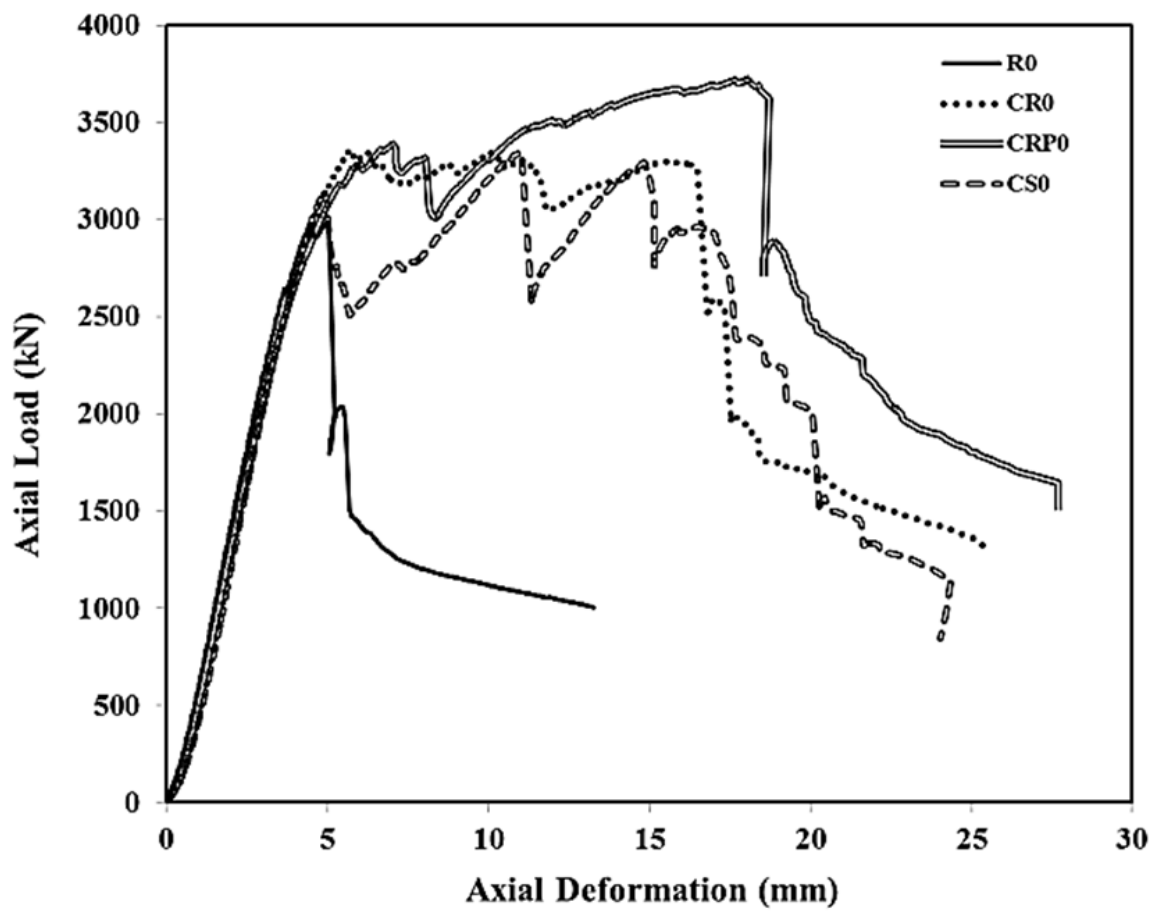

Figure 8 Axial load-Axial deformation diagrams of concentrically tested column specimens 

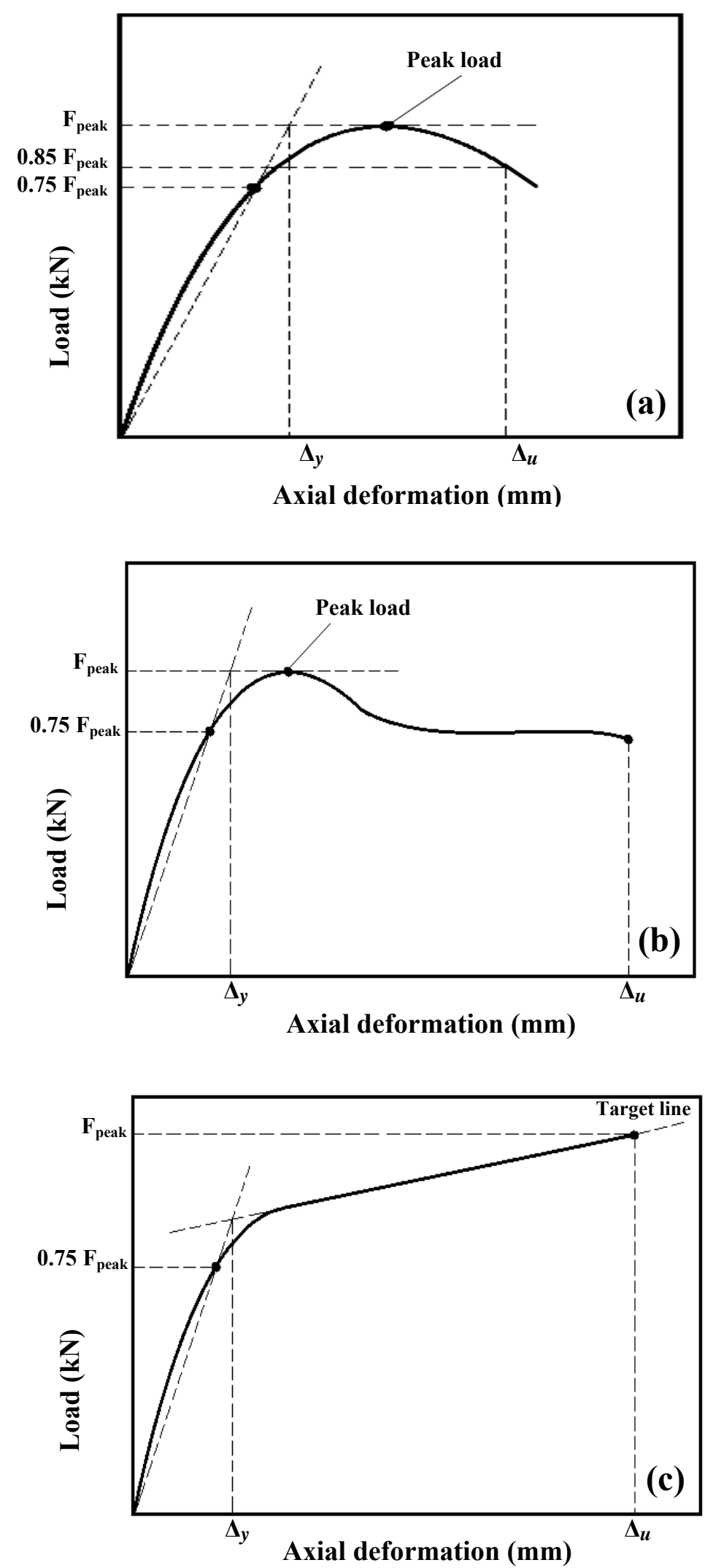

Figure 9 Definitions for yield and ultimate deformation (a) drop after yield; (b) softening after yield; (c) hardening after yield (Park 1989). 


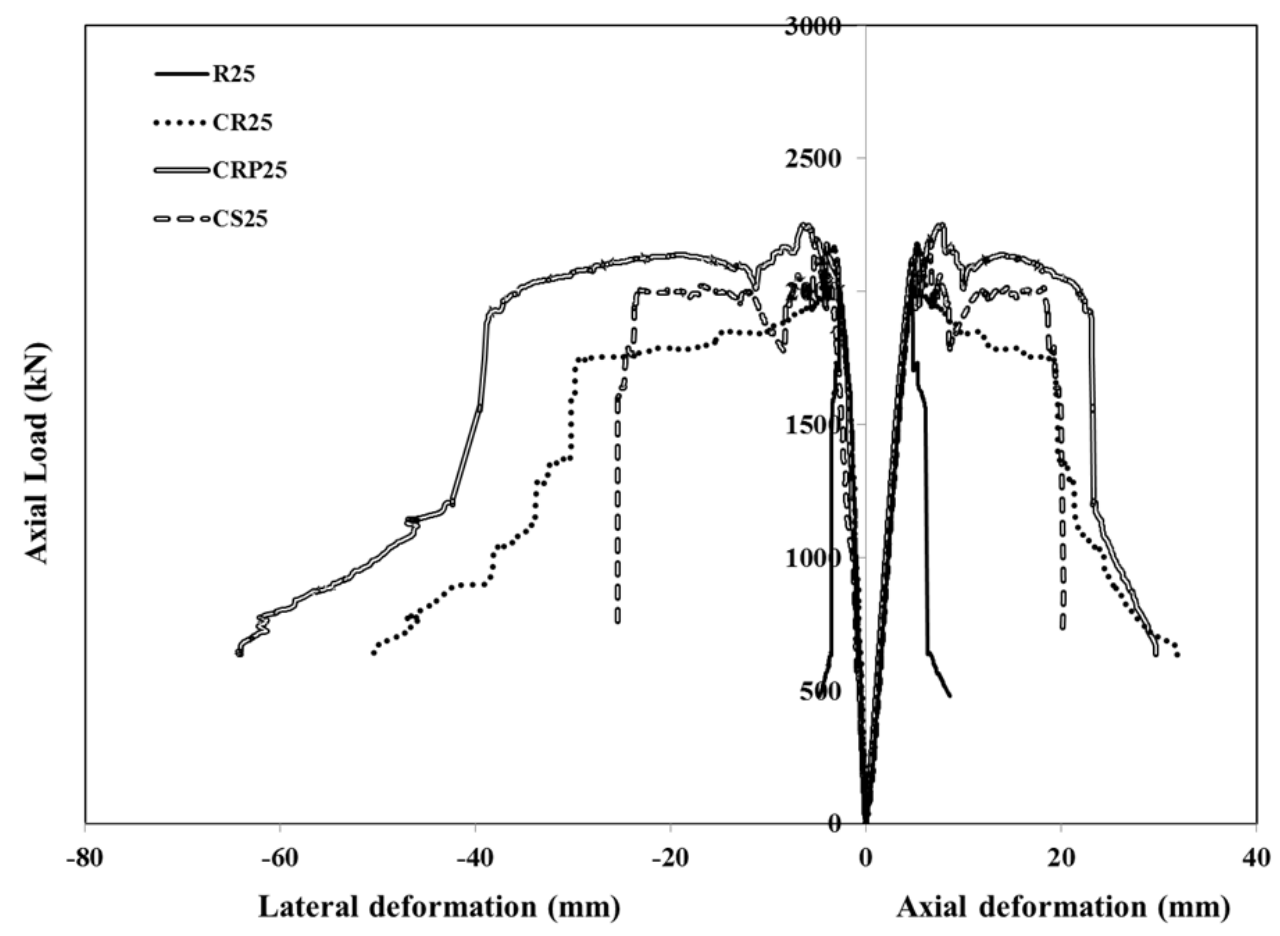

Figure 10 Axial load-deformation diagrams for column specimens tested under 25 mm eccentricity 


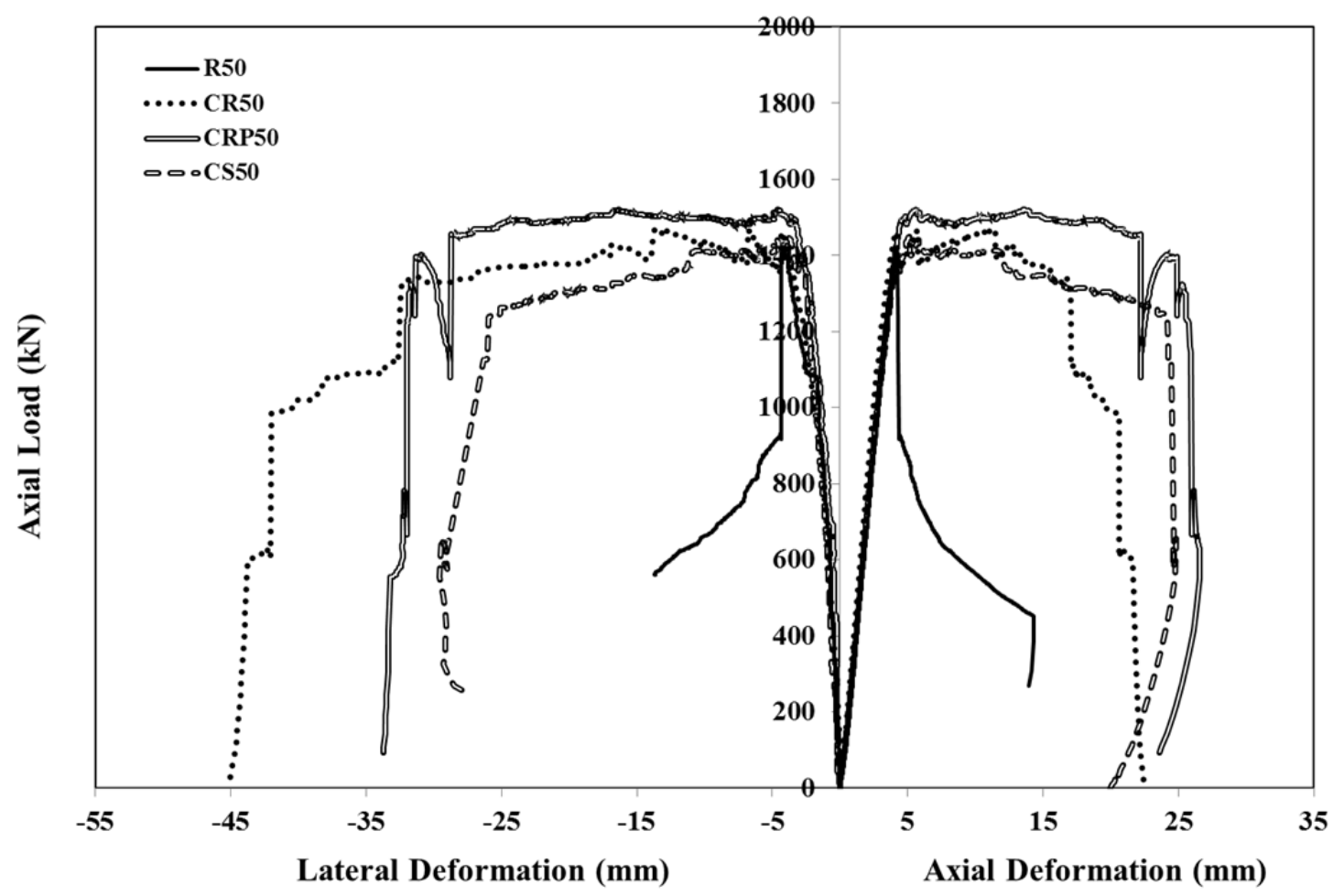

Figure 11 Axial load-deformation diagrams for column specimens tested under 50 mm eccentricity 


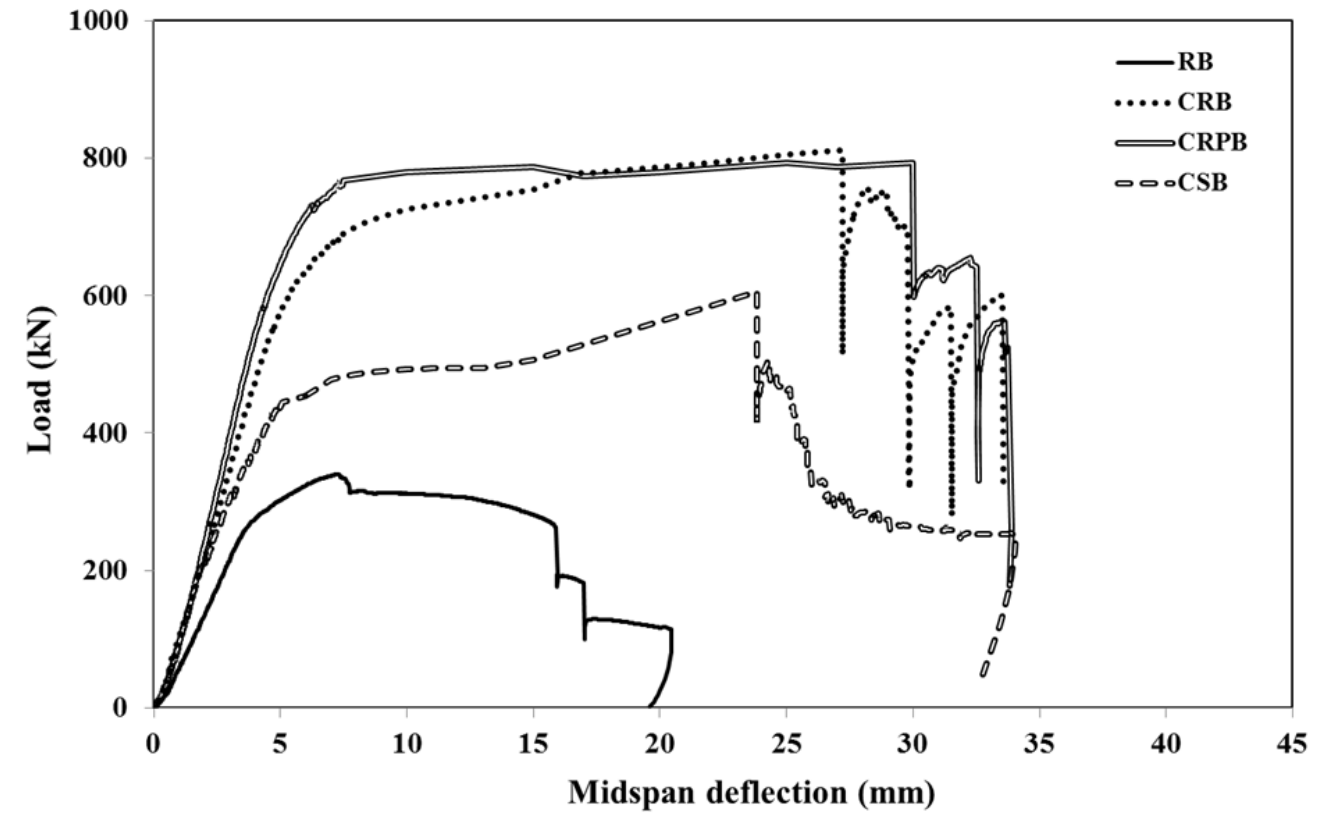

Figure 12 Load-midspan deflection diagrams for beam specimens tested under fourpoint bending 


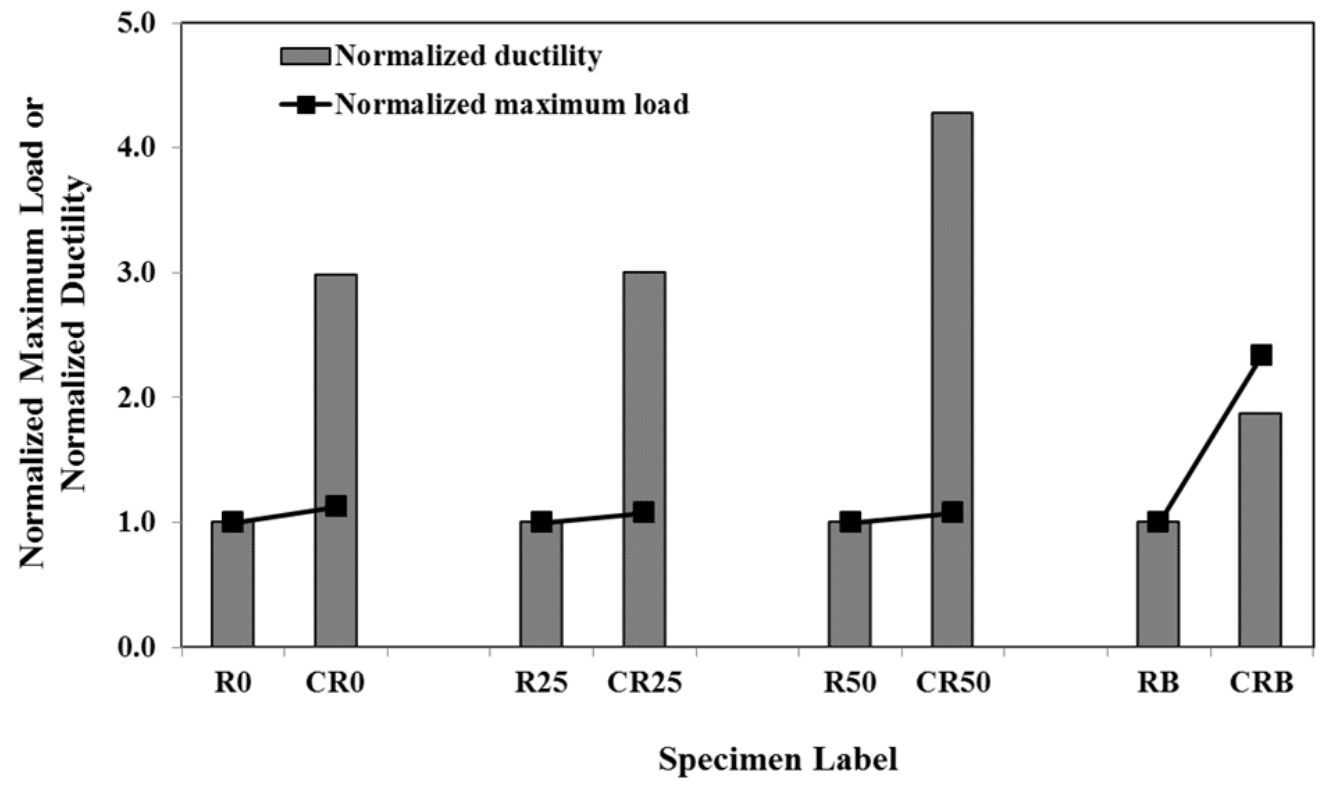

Figure 13 Effect of CFRP tube confinement on the maximum load and ductility of HCRPC specimens 


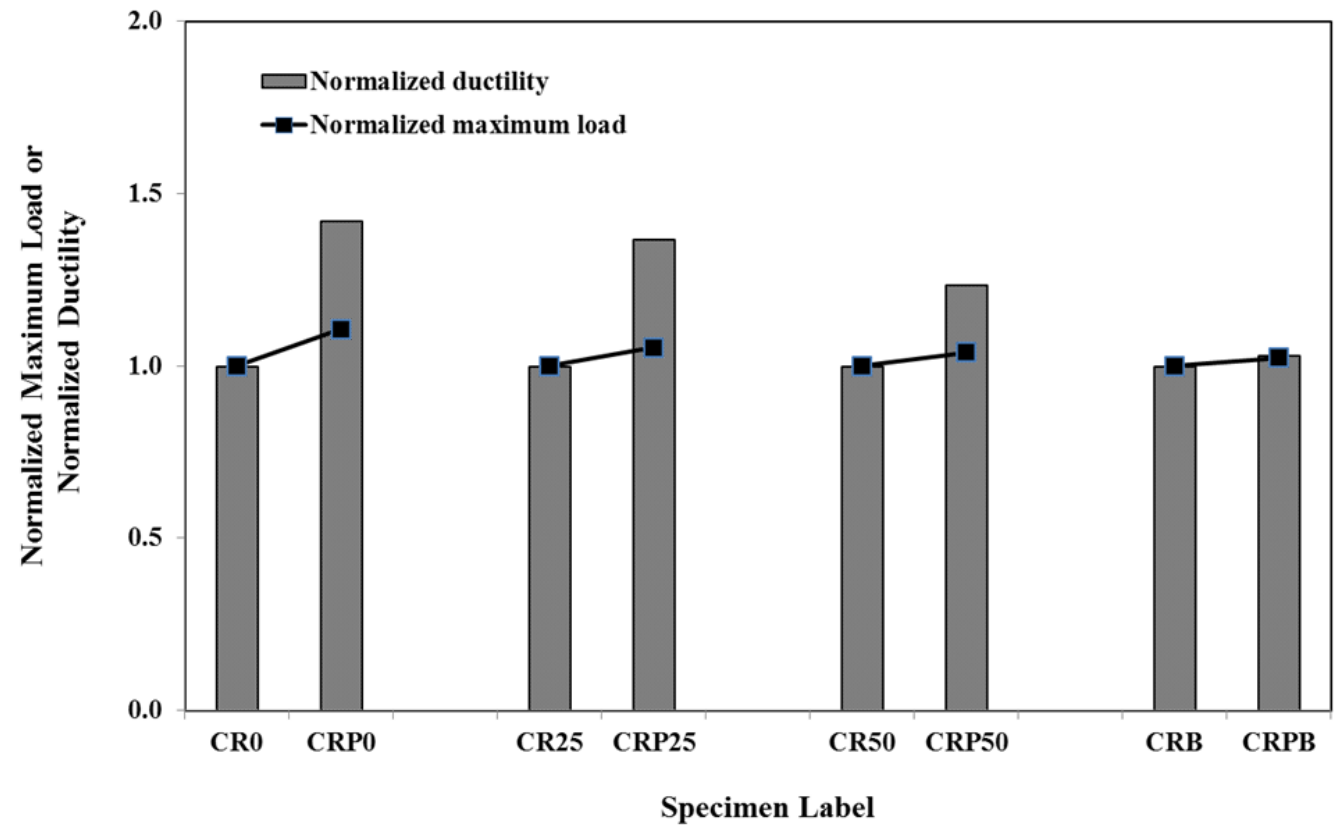

Figure 14 Effect of inner PVC tube on the maximum load and ductility of CFRPconfined HCRPC specimens 


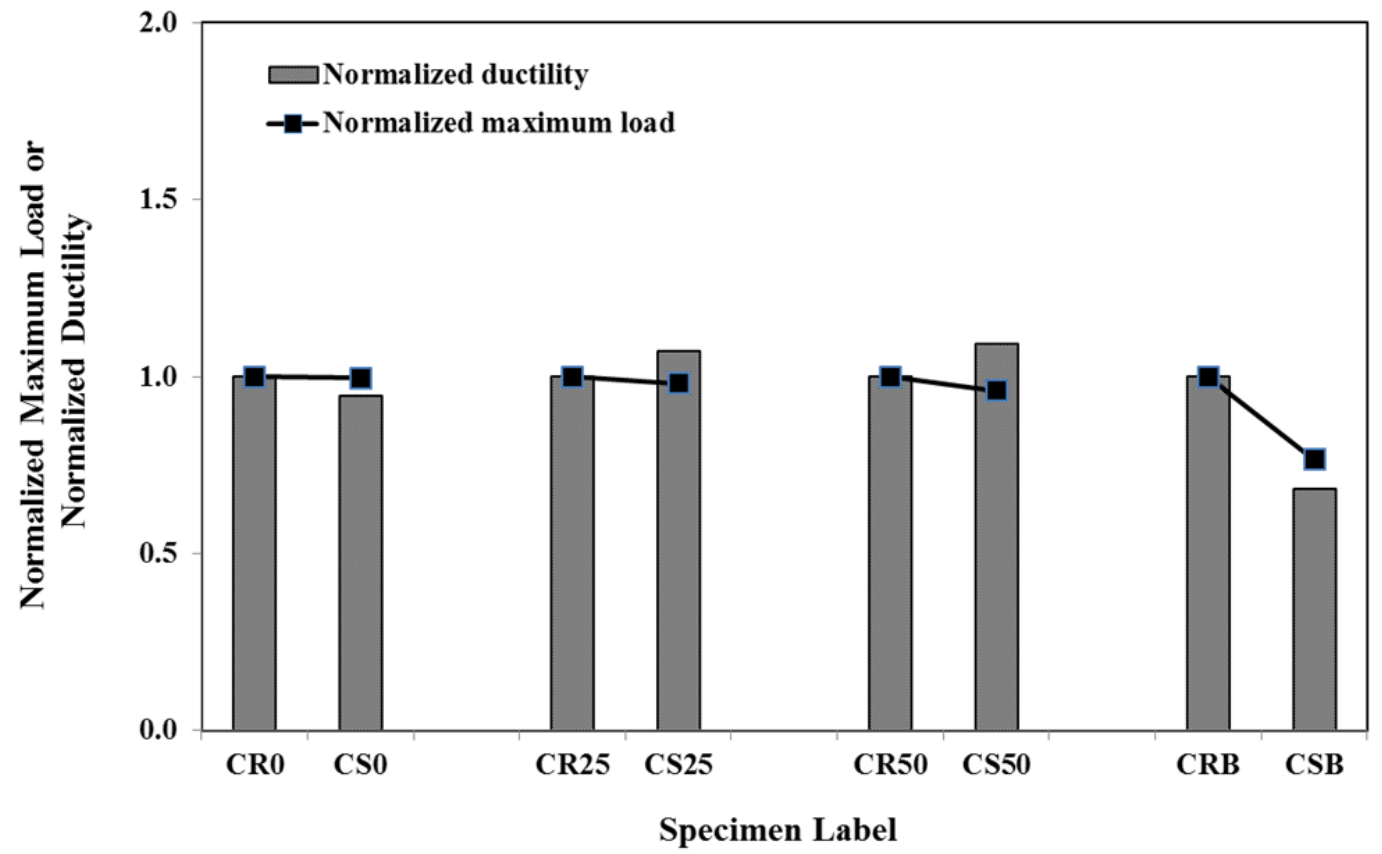

Figure 15 Effect of replacing normal steel reinforcement with steel tube on the maximum load and ductility of CFRP-confined HCRPC specimens 


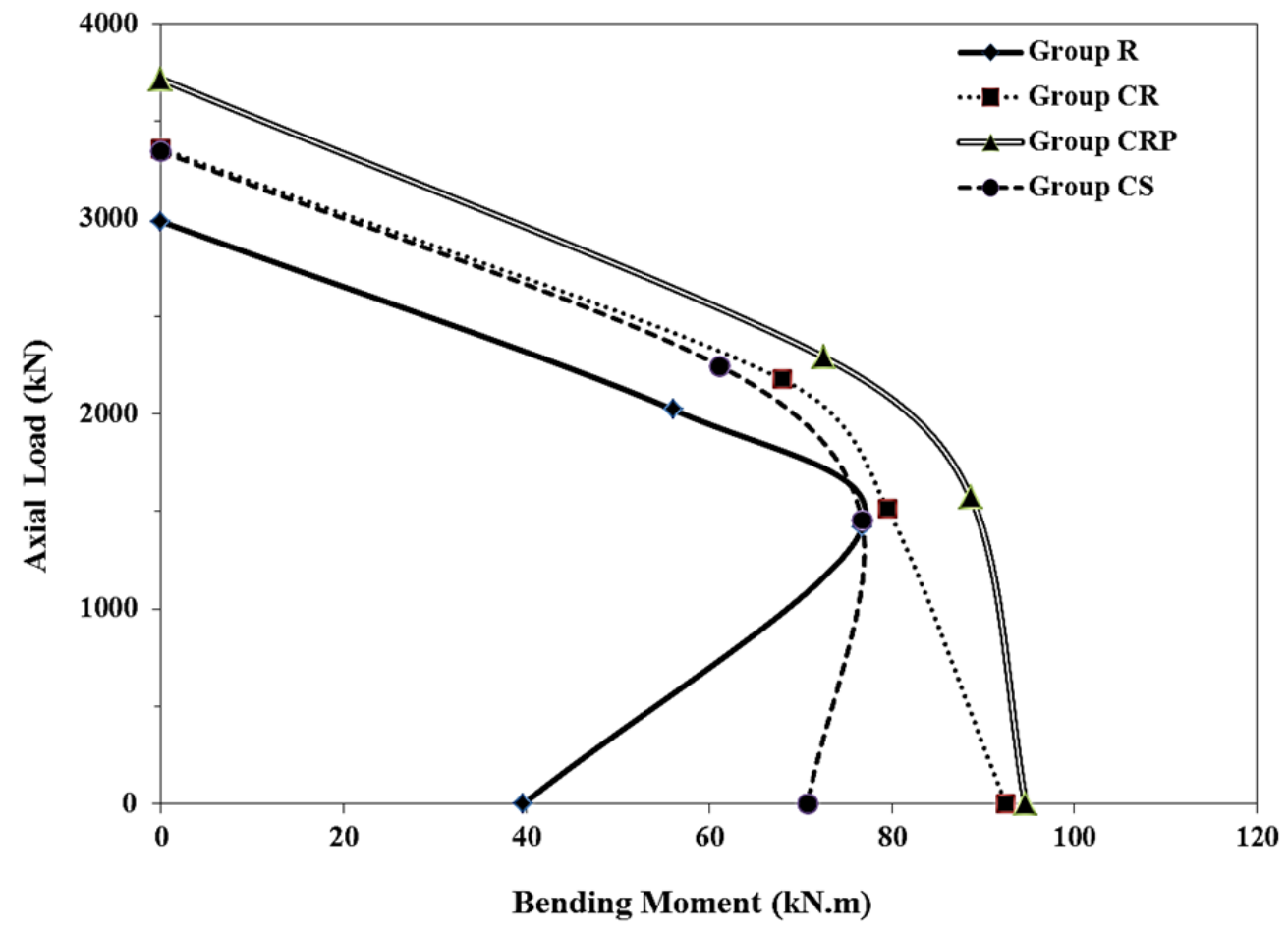

Figure 16 Experimental $P-M$ interaction diagrams of all HCRPC specimens 